\title{
Properties of polyvinyl alcohol nanocomposites reinforced with cellulose nanocrystals of red oak residues
}

Peter Michael Jacobson

West Virginia University

Follow this and additional works at: https://researchrepository.wvu.edu/etd

\section{Recommended Citation}

Jacobson, Peter Michael, "Properties of polyvinyl alcohol nanocomposites reinforced with cellulose nanocrystals of red oak residues" (2011). Graduate Theses, Dissertations, and Problem Reports. 3282. https://researchrepository.wvu.edu/etd/3282

This Thesis is protected by copyright and/or related rights. It has been brought to you by the The Research Repository @ WVU with permission from the rights-holder(s). You are free to use this Thesis in any way that is permitted by the copyright and related rights legislation that applies to your use. For other uses you must obtain permission from the rights-holder(s) directly, unless additional rights are indicated by a Creative Commons license in the record and/ or on the work itself. This Thesis has been accepted for inclusion in WVU Graduate Theses, Dissertations, and Problem Reports collection by an authorized administrator of The Research Repository @ WVU. For more information, please contact researchrepository@mail.wvu.edu. 


\title{
PROPERTIES OF POLYVINYL ALCOHOL NANOCOMPOSITES REINFORCED WITH CELLULOSE NANOCRYSTALS OF RED OAK RESIDUES
}

Peter Michael Jacobson

Thesis submitted to the

Davis College of Agriculture, Natural Resources, and Design

at West Virginia University

in partial fulfillment of the requirements

for the degree of

Master of Science

in

Forestry

\author{
Jingxin Wang, Ph.D., Chair \\ Qingzheng (George) Cheng, Ph.D. \\ David DeVallance, Ph.D. \\ Gloria Oporto, Ph.D. \\ Division of Forestry and Natural Resources
}

Morgantown, West Virginia

2011

Keywords: Biofilms; Cellulose Nanocrystals; Cellulosic Nanocomposites; Polyvinyl Alcohol; Woody Biomass 


\section{ABSTRACT \\ PROPERTIES OF POLYVINYL ALCOHOL NANOCOMPOSITES REINFORCED WITH CELLULOSE NANOCRYSTALS OF RED OAK RESIDUES}

\section{Peter Michael Jacobson}

Cellulose is an abundant, low cost, and robust biopolymer that is possible to implement in reinforcement of composite materials. Utilizing cellulosic nanocrystals, which can be isolated from cellulose fibers, nanocomposite biofilms are currently of interest to the packaging, medical, and pharmaceutical industries. At this time, hardwood cellulosic nanocrystals and nanocomposites are understudied. Therefore, this research characterized and examined the possibility of using hardwood residues for nanocomposite formation and implementation. Red oak (Quercus rubra) heartwood and sapwood residues were collected from 2005, 2006, and 2007 harvest sites located within West Virginia and were de-lignified by acidified sodium chlorite. Cellulosic nanocrystals were then isolated from the de-lignified red oak residues through a combination of sulfuric acid hydrolysis, ultrasonication, and homogenization. Upon isolation, nanocrystals were combined with a polyvinyl alcohol (PVA) matrix to form fully biodegradable cellulosic nanocomposite biofilms, via film casting. Morphology and thermal gravimetric results indicated that while de-lignification was a success, nanocrystal isolation was only partly successful, with some amorphous cellulose and lager cellulosic microfibrils remaining within the suspensions. Thermal gravimetric data also revealed that the composites experienced thermal degradation behaviors quite similar to their constituent materials. Tensile mechanical properties (strength and elastic modulus) of the nanocomposites were improved when compared to neat PVA; however, these increases in strength were coupled with decreases in elongation to break behaviors. Water vapor transmission rates were significantly decreased at the $2 \%$ and $6 \%$ loading levels, with the use of highly crystalline cellulose. Constructed composites did not hinder water vapor transmission at the $10 \%$ crystal loading level. Solubility testing revealed that cellulosic nanocomposites were able to remain intact at a wide range of temperatures, while being submerged in water, unlike neat PVA. All data found during this research suggested that any differences in properties of cellulosic nanocomposites, can be attributed to the initial processing methods used for nanocrystal isolation, not the year (2005, 2006, and 2007), or type (heartwood and sapwood) of materials used for biofilm formation. These materials are expected to be very useful for packaging and food barrier devices that are safe to the consumer and biodegradable. Formation of cellulosic nanocomposite biofilms utilizing red oak residues will benefit the wood industry by incorporating previously wasted materials into new environmental friendly products. 


\section{Acknowledgements}

I would like to thank Dr. Jingxin Wang, my major professor and advisor, for providing funding, time, and advice during my studies. I would also like to give a special thanks to Dr. Qingzheng (George) Cheng who has helped me a great deal during the past 2 years with all of my works, it would have been impossible for me to complete this research without his guidance. Also, I would like to thank Dr. David DeVallance and Dr. Gloria Oporto for helping me with the mechanical, water vapor transmission, and water solubility testing. Finally, I need to mention that during my past 6 years here ( 4 undergraduate and 2 graduate) that I have received help from all professors and staff within the Wood Science and Technology department, I could not have asked for a better group of people to spend my college years with. 


\section{TABLE OF CONTENTS}

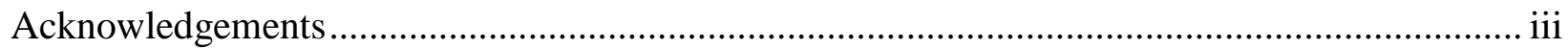

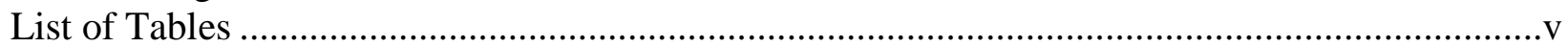

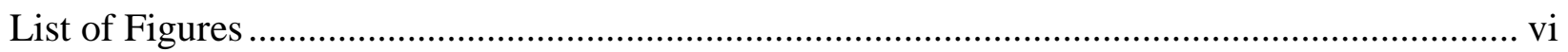

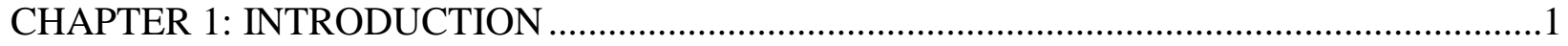

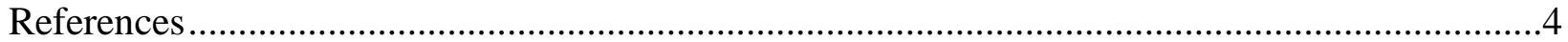

CHAPTER 2: CHARACTERIZATION OF RED OAK CELLULOSIC NANOCRYSTAL SUSPENSIONS AND COMPOSITES UTILIZING A POLYVINYL ALCOHOL MATRIX .......5

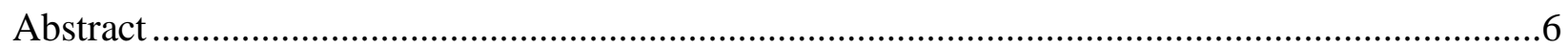

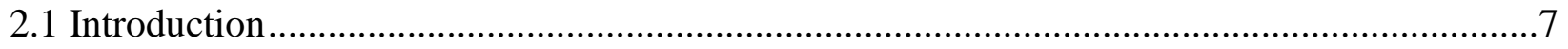

2.2 Materials and Methods............................................................................................

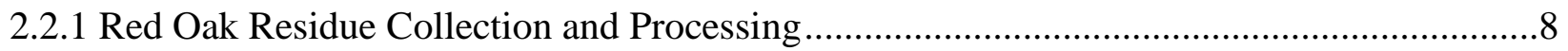

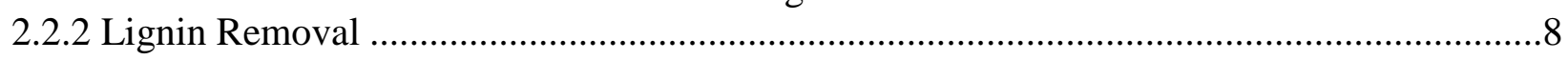

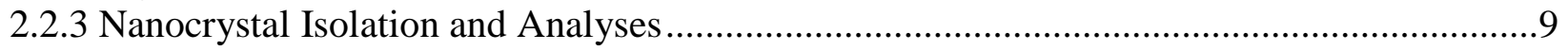

2.2.4 Polyvinyl Alcohol Solution Creation ............................................................................12

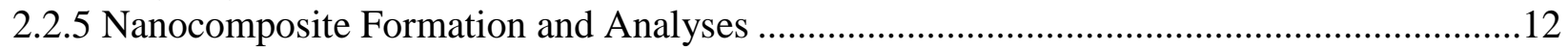

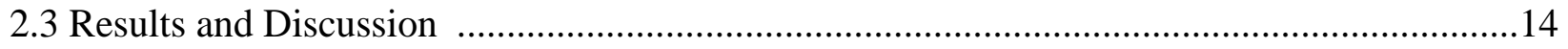

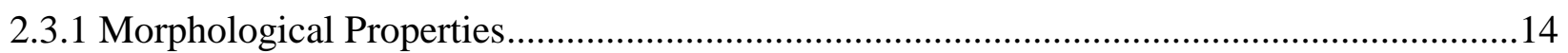

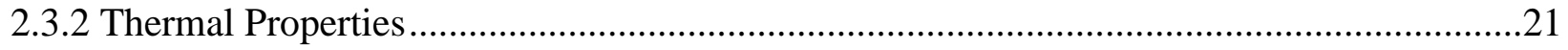

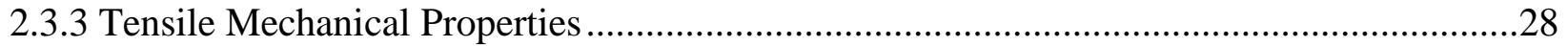

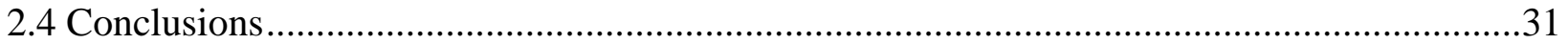

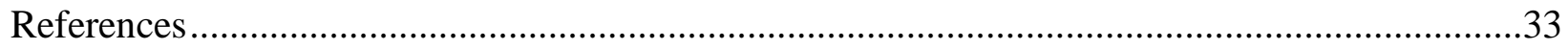

CHAPTER 3: WATER VAPOR TRANSMISSION AND SOLUBILITY PROPERTIES OF

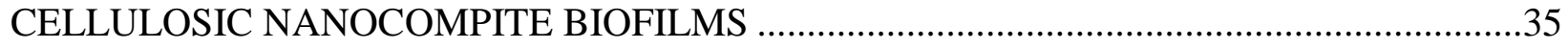

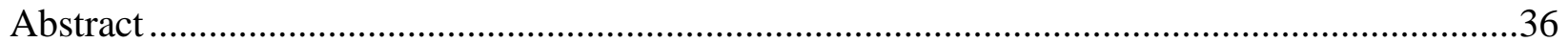

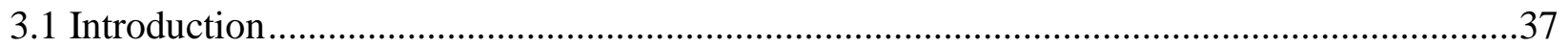

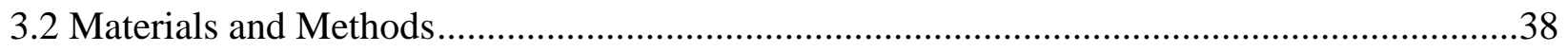

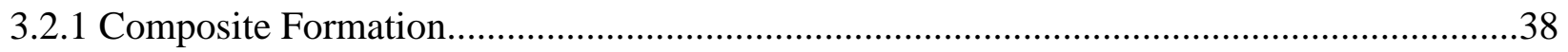

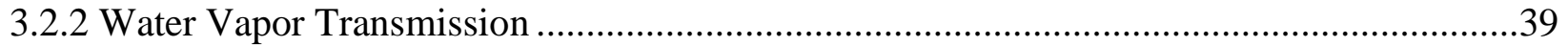

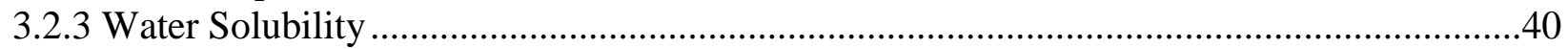

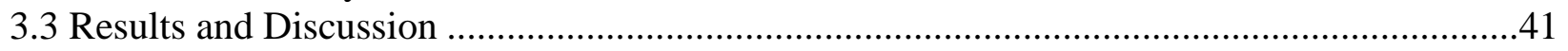

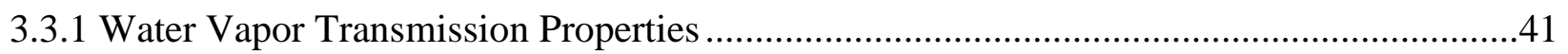

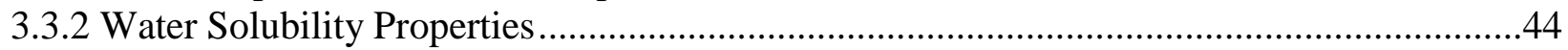

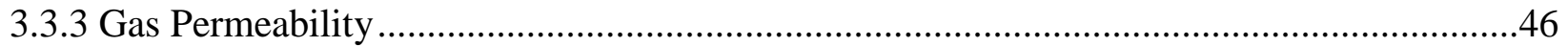

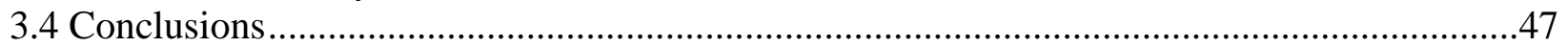

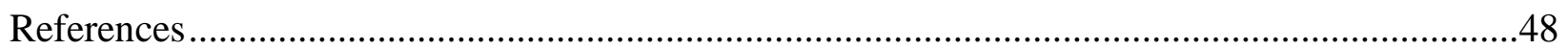

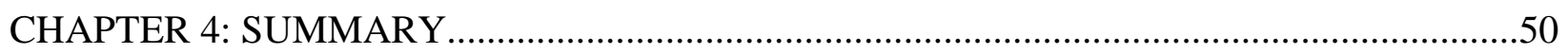




\section{LIST OF TABLES}

Table 2.1 Average sizes of red oak residues before and after lignin removal ............................14

Table 2.2 Yields of materials obtained after lignin removal ...............................................15

Table 2.3 Yields of materials obtained after nanocrystal isolation........................................20

Table 2.4 Summary of tensile mechanical data ..............................................................29

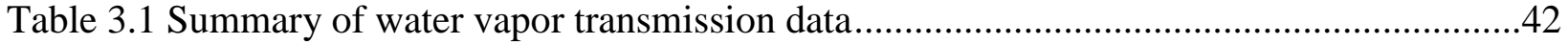

Table 3.2 Water vapor transmission data received from SMS Ltd........................................44 


\section{LIST OF FIGURES}

Figure 2.1 Light microscope images of (a) red oak 2005 (heartwood) residues and (b) lignin removed residues, at $100 \mathrm{X}$ magnifications

Figure 2.2 AFM images of red oak 2005 cellulose nanocrystal suspensions ..............................17

Figure 2.3 AFM images of red oak 2006 cellulose nanocrystal suspensions ............................18

Figure 2.4 AFM images of red oak 2007 cellulose nanocrystal suspensions .............................19

Figure 2.5 Percentage Weight Loss versus Temperature curvatures for red oak 2005 (heartwood)

residues, lignin removed residues, and cellulose nanocrystals

Figure 2.6 DTGA curves of red oak 2005 (heartwood) residues, lignin removed residues, and

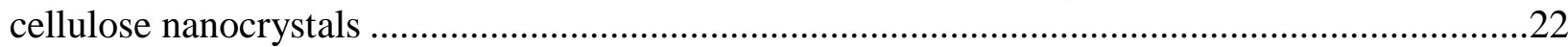

Figure 2.7 DTGA curves of cellulose 2005, 2006, and 2007 (heartwood) nanocrystals..............24

Figure 2.8 DTGA curves of cellulose 2005, 2006, and 2007 (sapwood) nanocrystals ................24

Figure 2.9 Percentage Weight Loss versus Temperature curvatures for cellulose 2005

(heartwood) nanocrystals, composites (2\%, 6\%, and 10\% loading levels), and PVA ...............25

Figure 2.10 Percentage Weight Loss versus Temperature curvatures for cellulose 2005 (sapwood) nanocrystals, composites ( $2 \%, 6 \%$, and $10 \%$ crystal loading levels), and PVA ........26 Figure 2.11 DTGA curves of cellulose 2005 (heartwood) nanocrystals, composites (2\%, 6\%, and

$10 \%$ loading levels), and PVA

Figure 2.12 DTGA curves of cellulose 2005 (sapwood) nanocrystals, composites $(2 \%, 6 \%$, and

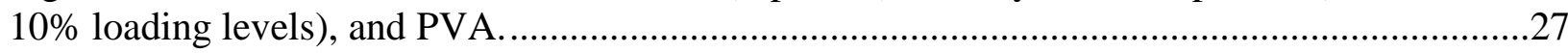

Figure 2.13 Summary of tensile mechanical data.............................................................28

Figure 2.14 Elongation behaviors of cellulose nanocomposites at 2\%, 6\%, and 10\%, crystal

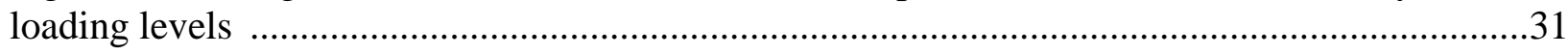

Figure 3.1 Summary of water vapor transmission data ................................................42

Figure 3.2 Water vapor pathway prevention via cellulose nanocrystals ...................................43

Figure 3.3 Summary of water solubility data.............................................................. 45 


\section{CHAPTER 1: INTRODUCTION}

Throughout the United States and much of the world, an emphasis on being "green", earth friendly, and environmentally conscientious has been the fore-front of many government, business, and public policies. In the past, the forest products industry has generally been viewed in a negative manner in regards to these environmentally sound practices. However, these attitudes are beginning to change as the general public is realizing that wood is not only a natural substance that is 100 percent bio-degradable (unlike many plastics), it is also a renewable or sustainable resource (unlike petroleum). To fully capitalize on this opportunity of shifting attitudes, the wood industry, while maintaining its traditional role in the housing and construction markets, must also concentrate on new bio-based or biocomposite products. One such product is known as a cellulosic nanocomposite which utilizes wood's primary building block, cellulose.

Cellulose is the most abundant natural biopolymer (polymers produced by living organisms) in the world (Cheng et al., 2008). It is found in plants, animals, bacteria, algae, and water molds (Hubbe et al., 2008). Using this plentiful resource in products such as nanocomposites has many advantages; such as renewability, low cost, good mechanical properties, low density, biodegradability, and recyclability (Freire and Gandini, 2006). If research and time is spent on the innovation and integration of cellulose into new bio-based products, the wood industry is sitting on a potential gold mine. Forty to fifty percent of wood's composition is cellulose (Forest Products Laboratory, 1999). Therefore, the wood industry already possesses an integral material needed to create new products such as cellulosic nanocomposites. 
A nanocomposite is defined as a composite that includes at least one component with a dimension (length, width, or thickness) at the nanometer scale (1 - 100 nanometers) (Cheng et al., 2008). In other words, the composite contains a material that in some dimension is 1 billionth or $10^{-9}$ of a meter $\left(3.281 \times 10^{-9}\right.$ foot $)$. In cellulosic nanocomposites, cellulose is treated with chemical, mechanical, or a combination of methods to isolate the crystalline region of the cellulose molecule, creating cellulose whiskers or nanocrystals (Wang and Cheng, 2009). Nanocrystals, which are comprised of several individual cellulose polymers, are used as filler material and combined with a matrix (ex. polyvinyl alcohol) to create a basic cellulosic nanocomposite. These cellulosic nanocomposite materials are possible to use in many applications including barrier films for packaging and several medical applications (Hubbe et al., 2008). Research and development in cellulosic nanocomposites is critical for these applications to become a reality, however, previous works indicate that the formation of these products can be quite problematic.

Although there are many benefits associated with the production of cellulosic nanocomposites using woody biomass, several obstacles are preventing the wood industry from producing these new composite products. Two specific obstacles in which this research addresses are; 1) Properties and behaviors of hardwood cellulose nanocrystal suspensions and nanocomposites, have not previously been examined in detail (Candanedo et al., 2005), and 2) The effects of incorporating hardwood cellulose nanocrystals into a polyvinyl alcohol matrix, in regards to barrier behaviors, are unknown. This study is designed to address these problems through the following objectives; 1) Characterize the properties of red oak cellulose nanocrystal suspensions and nanocomposites, and 2) Examine barrier behaviors of completed nanocomposites; including water vapor transmission and solubility. Upon completion, 
information gathered in this study will benefit the forest product industry's pursuit of new biocomposite products.

New innovative composites produced from wood will strengthen, diversify, and create new jobs within the forest products community. The goal of this study is to investigate the properties of a relatively new wood product, polyvinyl alcohol nanocomposites reinforced with cellulose nanocrystals of red oak residues. 


\section{References}

Candanedo, S.B., Roman, M., and Gray, D.G. (2005). Effect of reaction conditions on the properties and behavior of wood cellulose nanocrystal suspensions. Biomacromolecules, 6, 1048-1054.

Cheng, Q., Siqun, W., and Rials, T.G. (2008). Poly(vinyl alcohol) nanocomposites reinforced with cellulose fibrils isolated by high intensity ultrasonication. Composites: Part A, $40,218-224$.

Forest Products Laboratory. (1999). Wood handbook: wood as an engineering material. Chapter 3: Structure and Function of Wood. Madison, WI: U.S. Department of Agriculture, Forest Service, Forest Products laboratory.

Freire, C.S.R., and Gandini, A. (2006). Recent advances in the controlled heterogeneous modification of cellulose for the development of novel materials. Cellulose Chemistry and Technology, 40(9), 691-698.

Hubbe, M.A., Rojas, O.J., Lucia, L.A., and Sain, M. (2008). Cellulosic nanocomposites: a review. BioResources, 3(3), 929-980.

Wang, S., and Cheng, Q. (2009). A Novel process to isolate fibrils from cellulose fibers by highintensity ultrasonication, part 1: process optimization. Applied Polymer Science, 113, 1270-1275. 
CHAPTER 2: CHARACTERIZATION OF RED OAK CELLULOSIC NANOCRYSTAL SUSPENSIONS AND COMPOSITES UTILIZING A POLYVINYL ALCOHOL MATRIX

To be submitted to Wood and Fiber Science. 


\section{Abstract}

Red oak (heartwood and sapwood) residues were collected from 2005, 2006, and 2007 harvest sites located within West Virginia, milled to pass a 60 mesh sieve, and de-lignified by acidified sodium chlorite. Cellulosic nanocrystals were then isolated from the de-lignified red oak residues through a combination of sulfuric acid hydrolysis, ultrasonication, and homogenization. Upon isolation, nanocrystals were combined with a polyvinyl alcohol (PVA) matrix to form fully biodegradable cellulosic nanocomposite biofilms, via film casting. Morphology and thermal gravimetric results indicated that while de-lignification was a success, nanocrystal isolation was only partly successful, with some amorphous cellulose and lager cellulosic microfibrils remaining within the suspensions. Thermal gravimetric data also revealed that the composites experience thermal degradation behaviors that are quite similar to their constituent materials, at higher temperatures than neat PVA, but at lower temperatures than neat cellulosic nanocrystal suspensions. Tensile mechanical properties (strength and elastic modulus) of the nanocomposites were improved when compared to PVA; however, these increases in strength are coupled with decreases in elongation to break behaviors. Improvements in strength were not deemed significant with increases in crystal loading level $(2 \%, 6 \%$, and $10 \%)$ within the composites. These materials are expected to be useful as packaging for food and other products. Formation of cellulosic nanocomposite biofilms utilizing red oak residues will benefit the wood industry by incorporating previously wasted materials into new environmental friendly products. 


\subsection{Introduction}

The forest products industry has a long history within the state of West Virginia, as well as many economically successful operations. However, the wood industry is underutilizing available resources. One such resource is known as woody biomass, which mainly consists of any material produced by a tree; including roots, stems, branches, leaves, and needles. Woody biomass is present in the form of mill, harvesting, pulping, and agricultural residues, as well as energy crops and urban wood wastes. The majority of these biomass sources are available for use. For example in the United States, harvesting residues amount to 67 million dry tons annually, and of this, 41 million dry tons are available for recovery and use (USDOE and USDA, 2005). All of the woody biomass forms mentioned contain an integral component needed for cellulosic nanocomposite formation, cellulose, which constitutes approximately $50 \%$ of wood's substance (or woody biomass) by weight (Forest Products Laboratory, 1999).

Solid cellulose is comprised of amorphous (low order) and crystalline (high order) sections. Crystalline cellulose is composed of fiber molecules that are closely packed and parallel to one another. Amorphous cellulose contains fiber molecules that exhibit no real order or position. Crystalline regions provide cellulose with strength, hardness, and density, which in turn provide the cell wall with similar attributes (Lewin, 2007). These characteristics are optimal for structuring composite materials. Therefore, the isolation of cellulose, along with nanocrystal formation, is critical for nanocomposite production.

One problem associated with the formation and implementation of cellulose nanocrystal suspensions, as well as cellulosic nanocomposites, is the lack of information associated with hardwoods in this area of research (Candanedo et al., 2005). This study addresses this issue by 
conducting a characterization of red oak cellulosic nanocrystal suspensions and composites utilizing a polyvinyl alcohol matrix.

\subsection{Materials and Methods}

\subsubsection{Red Oak Residue Collection and Processing}

During the summer of 2007, red oak (Quercus rubra) residues were collected from 2005, 2006, and 2007 harvest sites located within West Virginia for processing (Adebayo et al., 2009). Once obtained, the materials were de-barked and oven-dried (Thermo Fisher Scientific, Model 6524) at $103{ }^{\circ}$ Celsius (C) until all moisture was removed from the samples. All materials were then ground using a Wiley Wood Mill (Thomas Scientific, Model ED-5) using a 1 millimeter (mm), or 0.03937 inch (in), diameter screen. The grinding process was repeated until the material passed a 60 mesh, 250 micron $(\mu \mathrm{m})$, sieve (U.S.A Standard Sieve Series, Model 11). Average sizes and morphologies of the wood fibers were obtained utilizing a light microscope (Fisher Scientific MicroMaster, Model 1256049) by taking pictures at several magnifications (10X, 20X, 40X, and 100X), and incorporating Fisher Scientifics' Micron software measurement tools. After obtaining the wood fiber measurements, lignin removal was performed.

\subsubsection{Lignin Removal}

Lignin removal was accomplished by a hydrolysis method adapted from (Kentaro et al., 2007), (Wise et al., 1946), utilizing $\mathrm{CH}_{3} \mathrm{COOH}$ (acetic acid, Fisher Scientific, A38S-500) and 
$\mathrm{NaClO}_{2}$ (sodium chlorite, Fisher Scientific, 7758-19-2) as reagents. Approximately 10 grams (g) of wood flour was added to 150 milliliters $(\mathrm{ml})$ of water. The flour and water mixture was then heated to $75{ }^{\circ} \mathrm{C}$ using a hot plate (Daigger Hot Plate / Stirrer, Model EF5035E). After the desired temperature was reached, $1 \mathrm{ml}$ of $\mathrm{CH}_{3} \mathrm{COOH}$ and $3 \mathrm{~g}$ of $\mathrm{NaClO}_{2}$ were added to the solution. Utilizing the magnetic stirrer on the hot plate, the solution was stirred for 1 hour, at which point another $1 \mathrm{ml}$ of $\mathrm{CH}_{3} \mathrm{COOH}$ and $3 \mathrm{~g}$ of $\mathrm{NaClO}_{2}$ were added. The process was completed 2 more times, for a total of 4 reagent additions. After the hydrolysis was complete, the solution was washed using distilled water by sitting approximately 10 times. Washing by centrifugation (accuSpin 400, Model 6524) at a speed of 1800 centrifugal forces (G), or 3630 revolutions per minute (RPM), and increasing times of 5 to 30 minutes took place until the mixture was acid free $(\mathrm{pH}=7)$. The product appeared yellowish-white upon completion. Using the measurement method described in section 2.2.1, average sizes and morphologies of the delignified residues were obtained. After lignin removal took place, nanocrystal isolation and analyses were completed.

\subsubsection{Nanocrystal Isolation and Analyses}

To isolate and analyze cellulosic nanocrystals, methods were adapted from (Cheng et al., 2007 and 2008), (Choi and Simosen, 2006). De-lignified red oak residues were placed in a 60\% (volume / volume) $\mathrm{H}_{2} \mathrm{SO}_{4}$ (sulfuric acid, Fisher Scientific, 7664-93-9) solution and heated using a hot plate to $45^{\circ} \mathrm{C}$, while utilizing the magnetic stirring mechanism to mix the materials. The cellulose to acid ratio was $1: 10 \mathrm{~g} / \mathrm{ml}$. Total time for hydrolysis was approximately 2 hours. The mixture was brown or coffee colored after hydrolysis (before washing). Upon completion of 
hydrolysis, the material was then centrifuged at speeds of $1800 \mathrm{G}$ and times of 30 to 60 minutes and decanted several times. A solution of $5 \% \mathrm{NaOH}$ (sodium hydroxide, Fisher Scientific, 131073-2) was added to the mixture to neutralize any remaining acids. Upon the completion of washing, the mixture was ivory colored. After a neutral $\mathrm{pH}$ (7) was obtained in the centrifugate, de-ionized water was added to the centrifuged solids and rinsed two - three times. Once rinsing was completed, the solids were suspended in de-ionized water and subjected to ultrasonic irradiation (Sonics \& Materials, 20 kilohertz (kHz), Model VCX 750) for 5 minutes at 50\% power to disperse the cellulose nanocrystals. The suspension was then further dispersed using homogenization (B.E.E. International, Model Nano Debee) at 137.89 megapascals (MPa) for 5 passes, de-ionized water was added as needed to complete the process. The aqueous suspension was then subjected to dialysis (Fisher Dialysis Tubing, Pore Size A-10) by placing the material inside tubing and submerging the containers in a bath of de-ionized water. The de-ionized water was changed once a day until the conductivity of the solution was less than 10 microseconds per centimeter $(\mu \mathrm{s} / \mathrm{cm}$ ), which was monitored with an Oakton Instruments (Model ECTester) handheld conductivity device. The solid content of the cellulose nanocrystal suspension was then calculated by measuring $5 \mathrm{~g}$ of material into 5 separate beakers (total of $25 \mathrm{~g}$ ) using a Denver MAXX scale (Model MXX -123), with a capacity of $120 \mathrm{~g}$ and a resolution of $0.001 \mathrm{~g}$. All 5 samples were then oven-dried at $103{ }^{\circ} \mathrm{C}$ for 24 hours. The following formula was used to calculate the cellulose nanocrystal solid contents: 
Where: $\mathbf{S C}=$ Solid content $(\%)$

$\mathbf{W M}=$ Wet Material $(\mathrm{g})$

DM = Dry Material $(\mathrm{g})$

Atomic Force Microscopy (AFM, Model Veeco Multimode) utilizing NanoScope software was used to examine the morphology and size of cellulose nanocrystals. A drop of suspension was placed on to a piece of mica which was stuck to a $9.5 \mathrm{~mm}$ steel puck, dried at room temperature for 24 hours, and then dried at $50{ }^{\circ} \mathrm{C}$ for another 2 hours. The AFM then utilized a silicon cantilever, in combination with a tapping mode of operation with a frequency of $148 \mathrm{kHz}$, to scan $1.0 \mu \mathrm{m}$ sections of the cellulosic nanocrystal samples dried on the mica. Images were obtained in both topography and phase modes of capturing. Thermal analysis of the suspensions was completed using a TA Instrument thermo gravimetric analyzer (TGA, Model Q50). Five samples were oven dried creating small films weighing between 2 - 3 milligrams (mg). After drying, the samples were placed in the TGA and heated from room temperature to $400{ }^{\circ} \mathrm{C}$ at a 20 ${ }^{\circ} \mathrm{C} /$ min heating rate (Choi and Simonsen, 2006). The tests were conducted under nitrogen gas to avoid oxidation. This thermal analysis process was also conducted using red oak residues, delignified residues, polyvinyl alcohol (PVA), and completed cellulosic nanocomposites, all weighing within the $2-3 \mathrm{mg}$ range. After all measurements were obtained, the materials were compared and contrasted in regards to thermal properties. 


\subsubsection{Polyvinyl Alcohol Solution Creation}

Procedures for the creation of PVA $10 \%$ (weight) solution for the nanocomposite matrix material were adapted from, (Flinn Scientific Incorporated, 2007). Using a hot plate, $360 \mathrm{ml}$ of distilled water was heated to $80-85^{\circ} \mathrm{C}$. Once the desired temperature was reached, $40 \mathrm{~g}$ of PVA crystals (Acros Organics, MFCD-00081922) were sprinkled into the hot water while utilizing the magnetic stirring mechanism. After all the crystals were added, the beaker was covered, and the heating process continued at $80-85^{\circ} \mathrm{C}$ for 2 - 4 hours or until the solution cleared. Any slimy or viscous layers appearing on the surface upon cooling were discarded (Cheng et al., 2007). Once the material cooled, it was ready to include in nanocomposite formation and analyses.

\subsubsection{Nanocomposite Formation and Analyses}

To calculate the correct amount (g) of PVA solution and cellulose nanocrystal suspensions needed for composite formation, the following values were determined; diameter of cast $(\mathrm{mm})$, area of cast $\left(\mathrm{mm}^{2}\right)$, PVA concentration (\% weight), nanocrystal concentration $(\%$ weight), PVA nominal density $\left(\mathrm{g} / \mathrm{mm}^{3}\right)$, nanocrystal nominal density $\left(\mathrm{g} / \mathrm{mm}^{3}\right)$, volume of cast $\left(\mathrm{mm}^{3}\right)$, and thickness of film $(\mu \mathrm{m})$. All length measurements were taken by a Fisherbrand electronic digital caliper (Model 06-664-16) with a resolution of $0.01 \mathrm{~mm}$, and all thickness measurements were taken by a Fowler electronic caliper (Model IP54) with a resolution of 0.001 mm. After measurements were obtained, the PVA solution and nanocrystal suspensions were mixed inside beakers at 3 different crystal loading levels; $2 \%, 6 \%$, and 10\%, and were consistent with (Cheng et al., 2007 and 2008). Mixing was accomplished manually and then further 
dispersed by ultrasonic treatment for 1 minute at $50 \%$ power. After mixing, the solutions were placed into Petri dishes and degassed in desiccators (Scienceware, Model F42020-0000) using a vacuum pump (Welch, 60 hertz (Hz), Model 25228-01), and evaporated at room temperature ( $20{ }^{\circ} \mathrm{C}$ ) and relative humidity (RH) of approximately $30 \%$ until films were formed. The films were then heat treated in an oven at $55^{\circ} \mathrm{C}$ for 6 hours. Upon cooling, composites were kept in sealed bags until testing was performed. Mechanical tension testing on the composites was performed following procedures outlined in “ASTM-D 1708-08”, (ASTM, 2008). Using a MTS universal test machine (Model 810, load cell capacity of $2.5 \mathrm{kN}(550 \mathrm{lb})$ ), utilizing electronics by Instron, testing was performed at a constant crosshead speed of $1 \mathrm{~mm} /$ minute (min). The crosshead extension was used as specimen deformation. Samples were cut to dog-bone shapes with widths of $5 \mathrm{~mm}$ for the narrow portions and total lengths of $40 \mathrm{~mm}$ (gauge length $20 \mathrm{~mm}$ ) using a Qualitest (Model 038446) die and press. Five specimens were prepared and tested for each composition (Cheng et al., 2008). Each tensile elastic modulus was determined as the tangent modulus from the linear portion of the stress-strain curves (initially unstable sections were ignored). The thermal analysis process described in section 2.2.3 that utilized the TA Instrument TGA was also undertaken to determine the thermal behaviors of the completed cellulosic nanocomposites. 


\subsection{Results and Discussion}

\subsubsection{Morphological Properties}

Initial processing of red oak 2005, 2006, and 2007 (heartwood and sapwood) residues produced particles that were small enough to pass a 60 mesh sieve. Average sizes (lengths and widths) of residues after initial processing are given in Table 2.1.

Table 2.1. Average sizes of red oak residues before and after lignin removal.

\begin{tabular}{lcccc}
\hline \multicolumn{1}{c}{ Specimen } & $\begin{array}{c}\text { Residue } \\
\text { Length } \\
(\mu \mathrm{m})\end{array}$ & $\begin{array}{c}\text { Lignin Removed } \\
\text { Length } \\
(\mu \mathrm{m})\end{array}$ & $\begin{array}{c}\text { Residue } \\
\text { Width } \\
(\mu \mathrm{m})\end{array}$ & $\begin{array}{c}\text { Lignin Removed } \\
\text { Width } \\
(\mu \mathrm{m})\end{array}$ \\
\hline Red oak 2005 (heartwood) & $13.98 \pm 10.54$ & $11.67 \pm 9.67$ & $4.01 \pm 2.11$ & $3.66 \pm 2.57$ \\
Red oak 2005 (sapwood) & $13.75 \pm 10.35$ & $11.53 \pm 9.54$ & $3.96 \pm 2.15$ & $3.59 \pm 1.49$ \\
Red oak 2006 (heartwood) & $13.56 \pm 10.21$ & $11.59 \pm 9.57$ & $3.87 \pm 2.01$ & $3.57 \pm 2.18$ \\
Red oak 2006 (sapwood) & $14.01 \pm 10.67$ & $11.77 \pm 9.83$ & $4.21 \pm 2.40$ & $3.82 \pm 1.98$ \\
Red oak 2007 (heartwood) & $12.99 \pm 10.04$ & $11.34 \pm 9.41$ & $3.85 \pm 2.38$ & $3.46 \pm 1.67$ \\
Red oak 2007 (sapwood) & $13.54 \pm 10.17$ & $11.46 \pm 9.48$ & $3.95 \pm 2.39$ & $3.61 \pm 2.45$ \\
\hline Standard Deviation, 100 measurements taken of each specimen & &
\end{tabular}

It is apparent from Table 2.1 that all specimens, regardless of year or type (heartwood and sapwood) are of the same general average size, which was expected considering all residues underwent the same processing and sieving operation. After lignin removal took place, specimens became slightly smaller but again, there is no significant $(\alpha=0.05)$ difference 
between year or type in regards to average size. These results along with yields received after lignin removal (Table 2.2), indicate that the de-lignification method is not affected by the year or type or residue.

Table 2.2. Yields of materials obtained after lignin removal.

\begin{tabular}{lccc}
\hline \multicolumn{1}{c}{ Specimen } & $\begin{array}{c}\text { Initial Mass } \\
(\mathrm{g})\end{array}$ & $\begin{array}{c}\text { Lignin Removed Mass } \\
(\mathrm{g})\end{array}$ & $\begin{array}{c}\text { Lignin Removed Yield } \\
(\%)\end{array}$ \\
\hline Red oak 2005 (heartwood) & 30.00 & 18.99 & $63.33 \%$ \\
Red oak 2005 (sapwood) & 30.00 & 18.78 & $62.60 \%$ \\
Red oak 2006 (heartwood) & 30.00 & 17.98 & $59.93 \%$ \\
Red oak 2006 (sapwood) & 30.00 & 18.12 & $60.40 \%$ \\
Red oak 2007 (heartwood) & 30.00 & 17.66 & $58.89 \%$ \\
Red oak 2007 (sapwood) & 30.00 & 19.01 & $63.37 \%$ \\
\hline
\end{tabular}

Figures 2.1 illustrates the morphology and measurement process of red oak residues (left) and lignin removed residues (right). Other years and types of residues were similar in size and shape. 


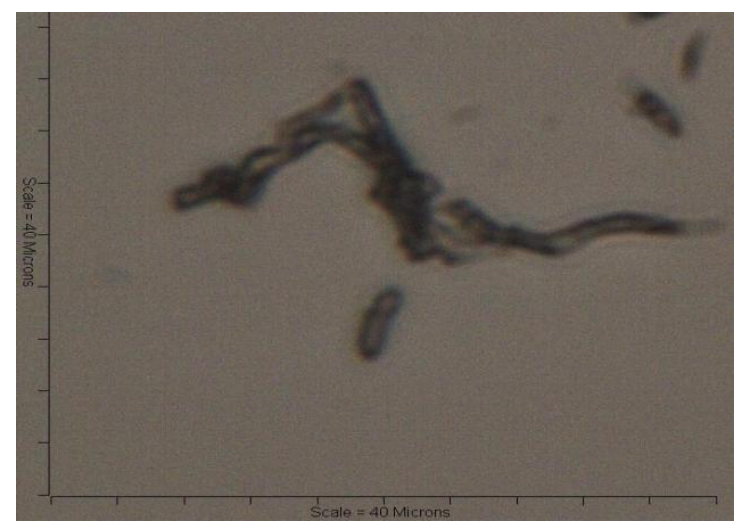

(a)

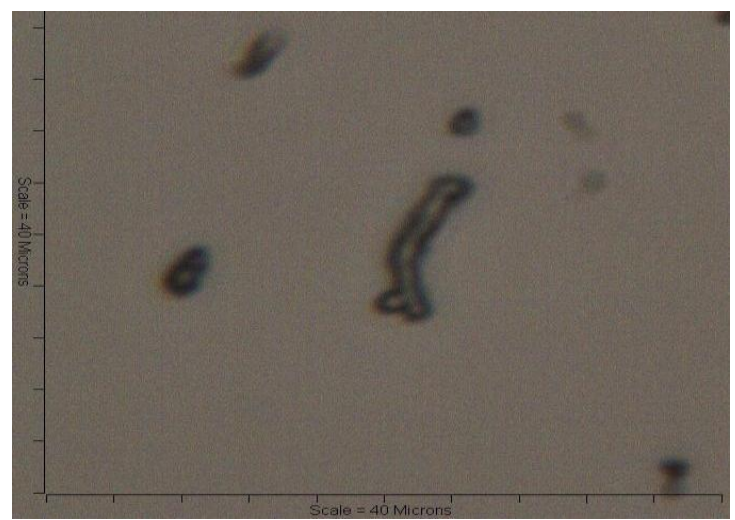

(b)

Figure 2.1. Light microscope images of (a) red oak 2005 (heartwood) residues and (b) lignin removed residues (right), at 100X magnifications.

Atomic force microscopy topography (left) and phase (right) images of cellulosic nanocrystal suspensions are given in Figures 2.2, 2.3, and 2.4. 


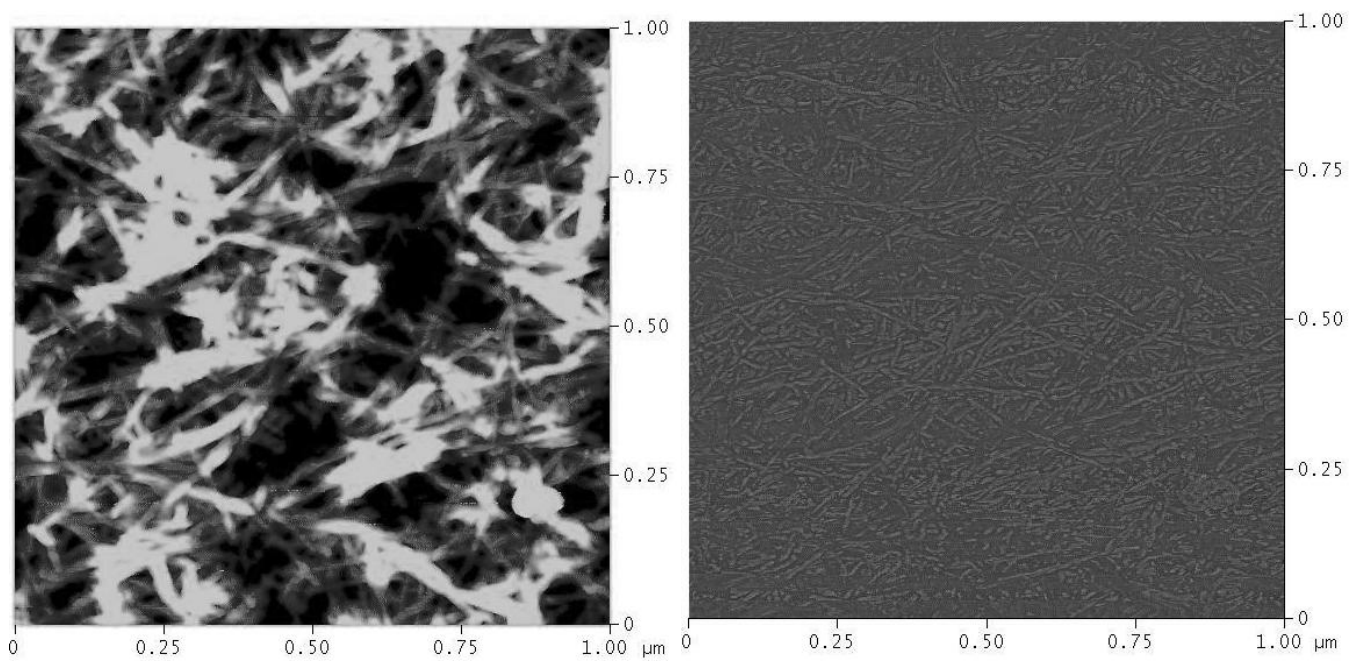

(a) red oak 2005 (heartwood)

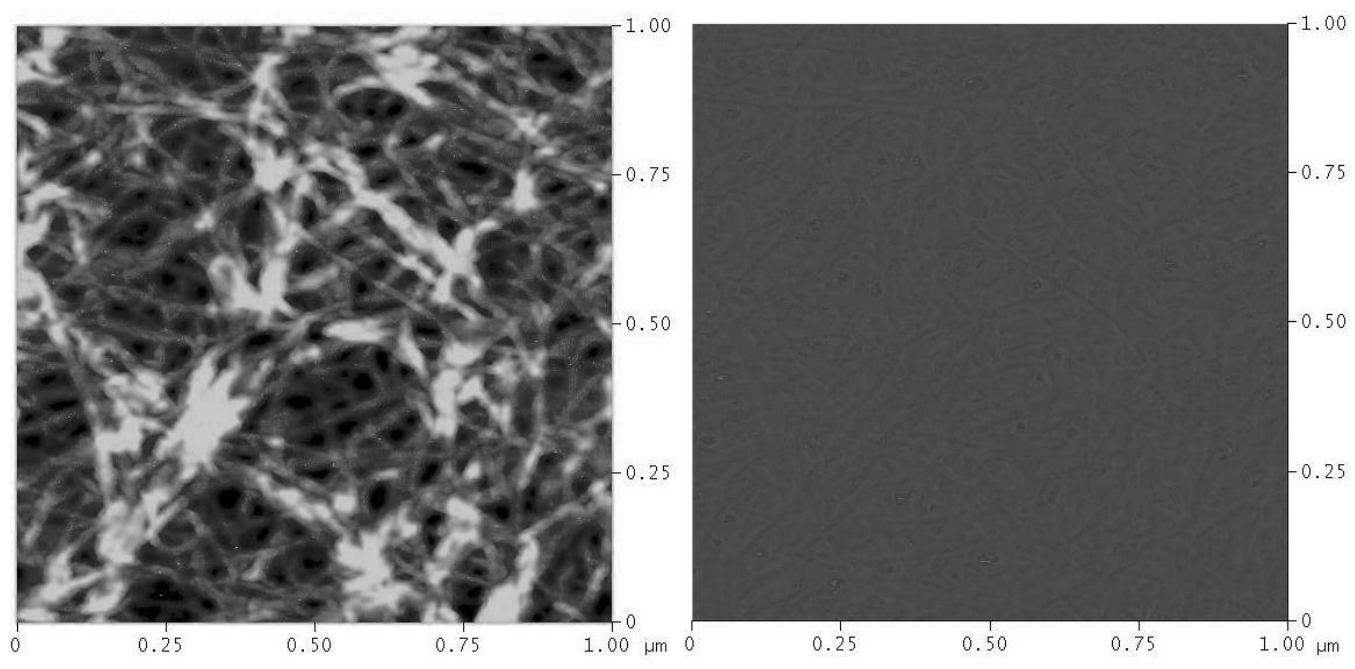

(b) red oak 2005 (sapwood)

Figure 2.2. AFM images of red oak 2005 cellulose nanocrystal suspensions topography (left) and phase (right). 


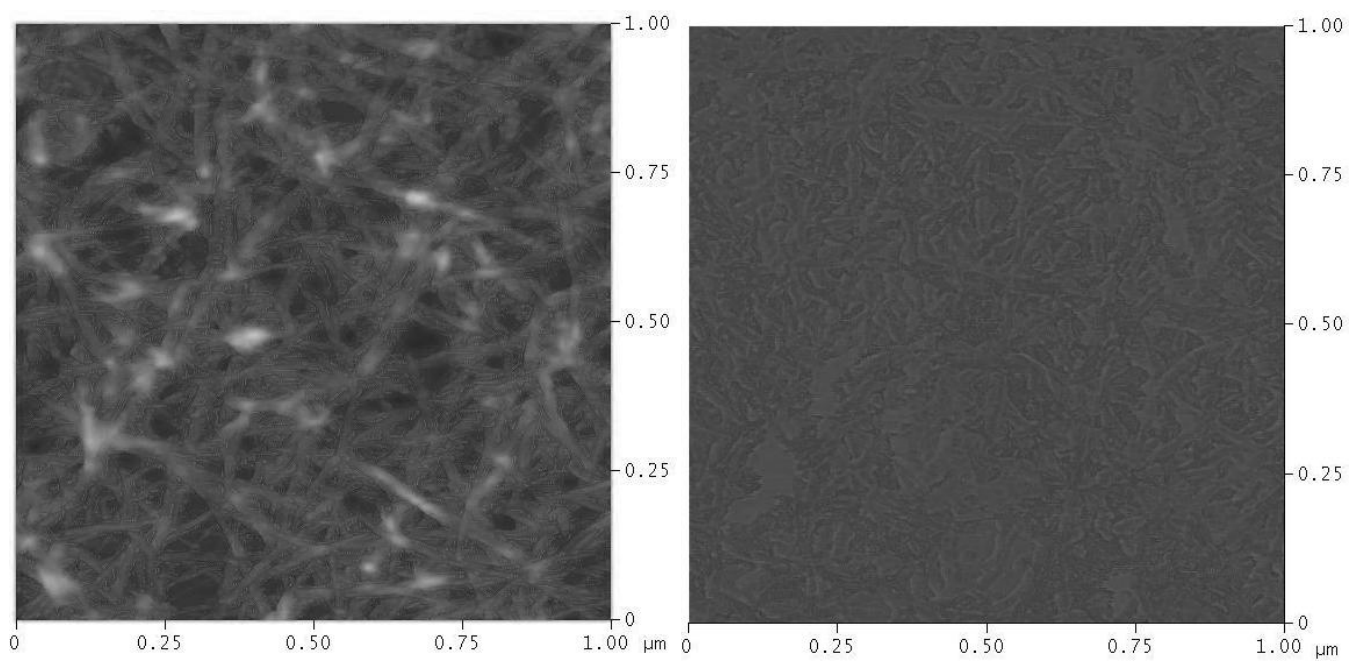

(a) red oak 2006 (heartwood)

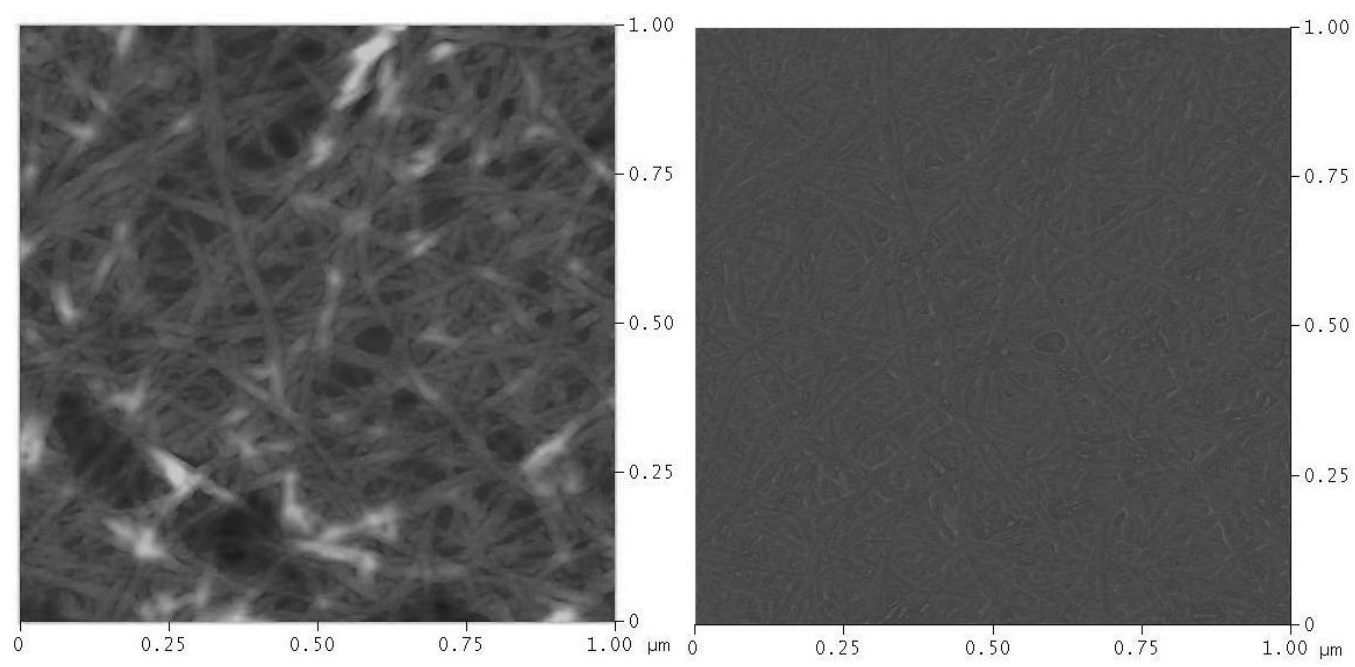

(b) red oak 2006 (sapwood)

Figure 2.3. AFM images of red oak 2006 cellulose nanocrystal suspensions topography (left) and phase (right). 


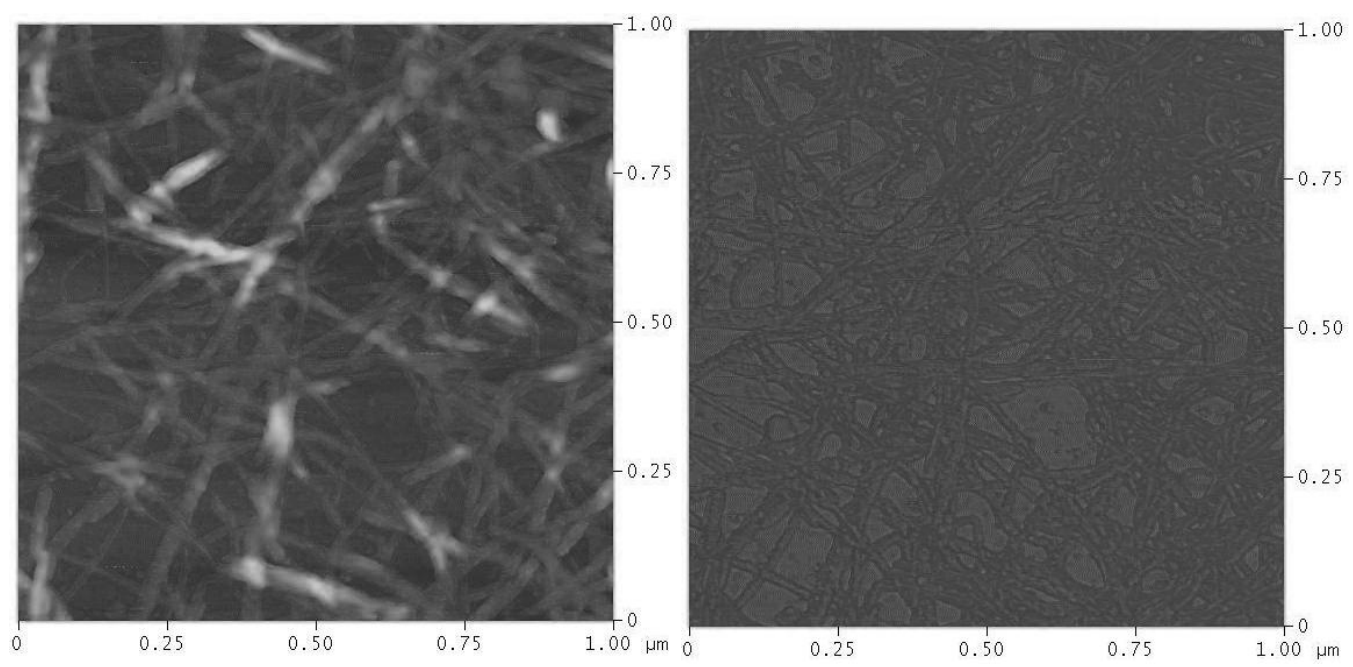

(a) red oak 2007 (heartwood)
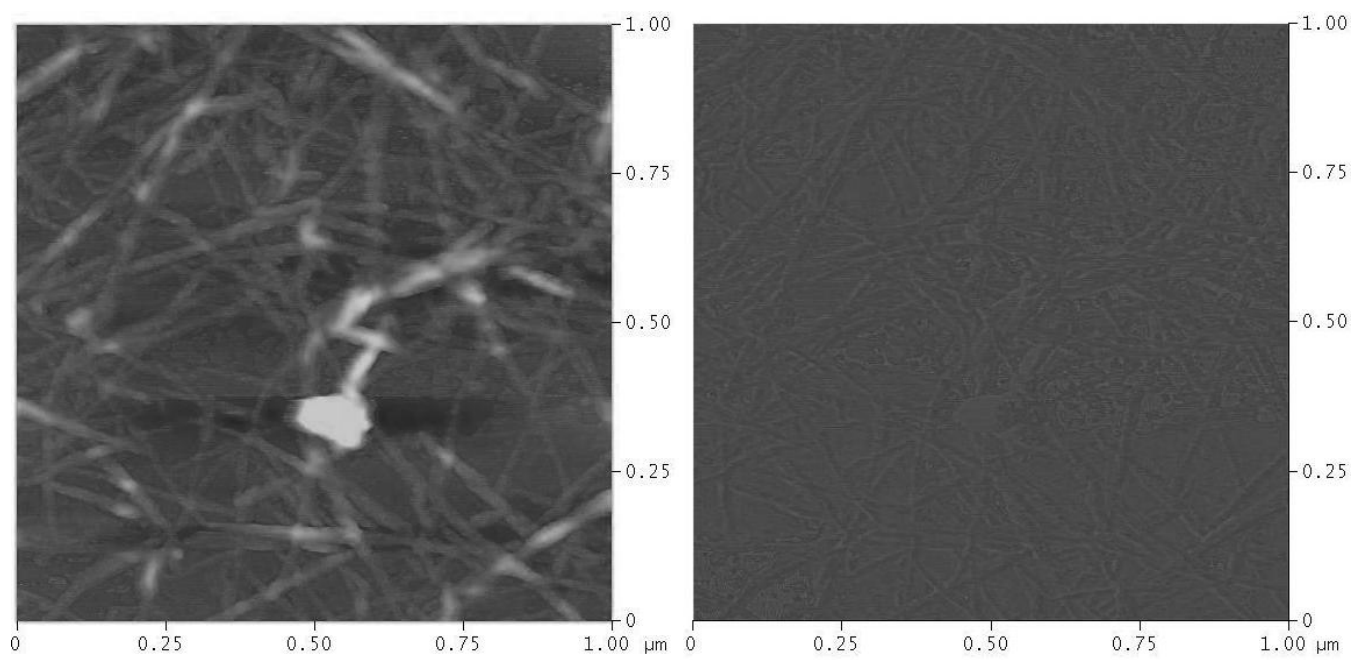

(b) red oak 2007(sapwood)

Figure 2.4. AFM images of red oak 2007 cellulose nanocrystal suspensions topography (left) and phase (right).

Captures received via AFM imagery indicate that the nanocrystal isolation process utilizing acid hydrolysis did not fully hydrolyze the cellulosic microfibrils into individual nanocrystals as 
every specimen contains particles that are well over 2 - $3 \mu \mathrm{m}$, or 2,000 - 3,000 nanometers (nm), in length. Individual cellulose nanocrystal lengths should be in the range of $100-300 \mathrm{~nm}$ (Candanedo et al., 2005). This lack of crystallization (in regards to length) also indicates that there are varying amounts of amorphous regions of cellulose present within the nanocrystal suspensions, which is confirmed by the high variability in yields received after nanocrystal isolation (Table 2.3). Widths (or diameters) of crystalline samples appeared to be nano-scale (1 $100 \mathrm{~nm}$ ) in nature.

Table 2.3. Yields of materials obtained after nanocrystal isolation.

\begin{tabular}{cccc}
\hline $\begin{array}{c}\text { Lignin Removed } \\
\text { Specimen }\end{array}$ & $\begin{array}{c}\text { Initial Mass } \\
(\mathrm{g})\end{array}$ & $\begin{array}{c}\text { Nanocrystal Mass } \\
(\mathrm{g})\end{array}$ & $\begin{array}{c}\text { Nanocrystal Yield } \\
(\%)\end{array}$ \\
\hline Red oak 2005 (heartwood) & 15.00 & 7.80 & $52.00 \%$ \\
Red oak 2005 (sapwood) & 15.00 & 2.75 & $18.33 \%$ \\
Red oak 2006 (heartwood) & 15.00 & 1.89 & $12.60 \%$ \\
Red oak 2006 (sapwood) & 15.00 & 3.50 & $23.33 \%$ \\
Red oak 2007 (heartwood) & 15.00 & 1.56 & $10.40 \%$ \\
Red oak 2007 (sapwood) & 15.00 & 1.80 & $12.00 \%$ \\
\hline
\end{tabular}

Table 2.3, along with thermal data in section 2.3.2, suggest that the 2 samples which contain the greatest amount of amorphous cellulose are red oak 2005 (heartwood), and red oak 2006 (sapwood). This information indicates that the degree of amorphous cellulose contained in samples after nanocrystal isolation does not depend upon year or type in regards to final product yield. Literature indicates that naturally occurring wood cellulose contains $50-65 \%$ crystalline 
materials (Lewin, 2007), so theoretically all yields received are possible, however, the method of washing used in this research is very inefficient. This inefficiently is mainly attributed to the low maximum speed of the centrifuge which did not allow for the proper separation of materials. Incomplete acid hydrolysis coupled with the inefficiently of the washing mechanism, allowed for these amorphous sections to remain within the nanocrystal suspensions.

\subsubsection{Thermal Properties}

It is important to note that each material used in composite construction thermally degrades at the following temperatures; cellulose $\left(240-350{ }^{\circ} \mathrm{C}\right)$, hemicellulose $\left(130-194{ }^{\circ} \mathrm{C}\right)$, lignin $\left(280-500{ }^{\circ} \mathrm{C}\right)$, and polyvinyl alcohol $\left(200-300{ }^{\circ} \mathrm{C}\right)$, (Singh, 2010), (Holland and Hay, 2001). Two types of curvatures are used to characterize thermal properties of all composite constituents and completed nanocomposites. Curvature types are as follows; Percentage Weight Loss versus Temperature curves, and differential thermo gravimetric curves or DTGA curves, where percentage weight was differentiated with respect to temperature. Figure 2.5 reveals that red oak 2005 (heartwood), lignin removed resides, and cellulose nanocrystals all degrade in a similar fashion or pattern, with thermal decomposition beginning in the temperature range of 230 - $270{ }^{\circ} \mathrm{C}$ (ignoring initial moisture loss). Similar Percentage Weight Loss versus Temperature

curves occurred for all years $(2005,2006$, and 2007) and for both heartwood and sapwood residues. 


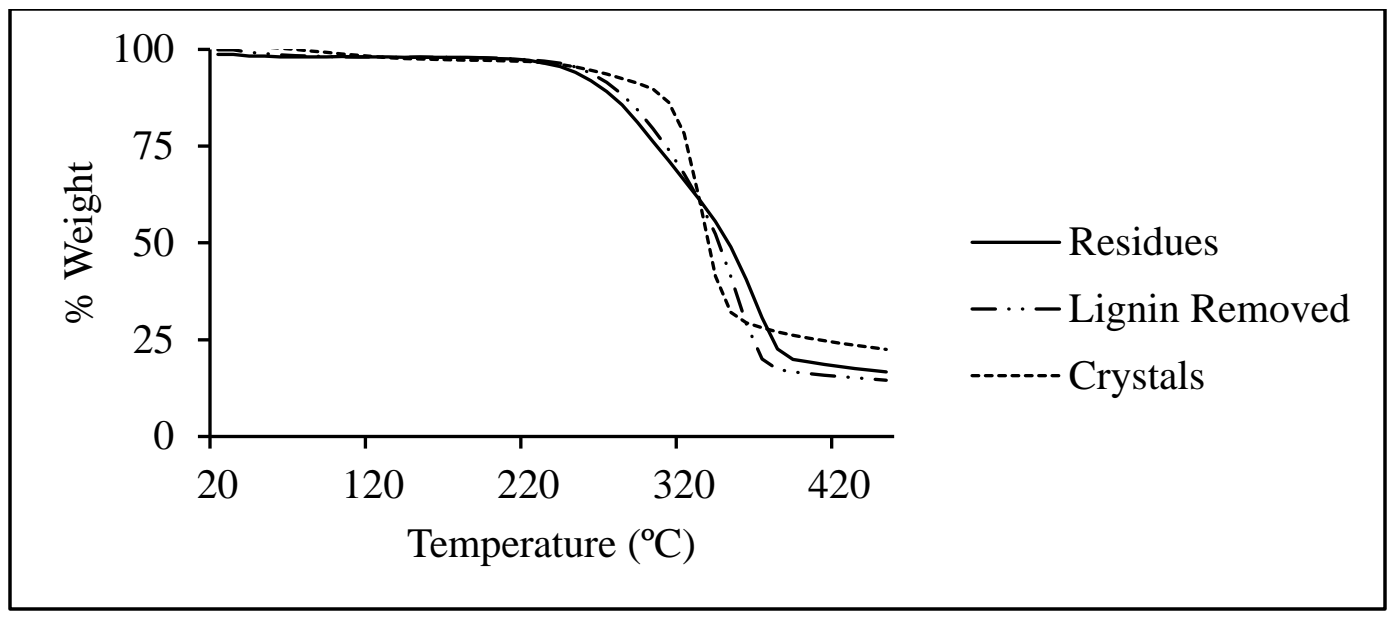

Figure 2.5. Percentage Weight Loss versus Temperature curvatures for red oak 2005 (heartwood) residues, lignin removed residues, and cellulose nanocrystals.

However, DTGA curves of the same data reveals differences in thermal degradation behavior between each of the raw materials (Figure 2.6).

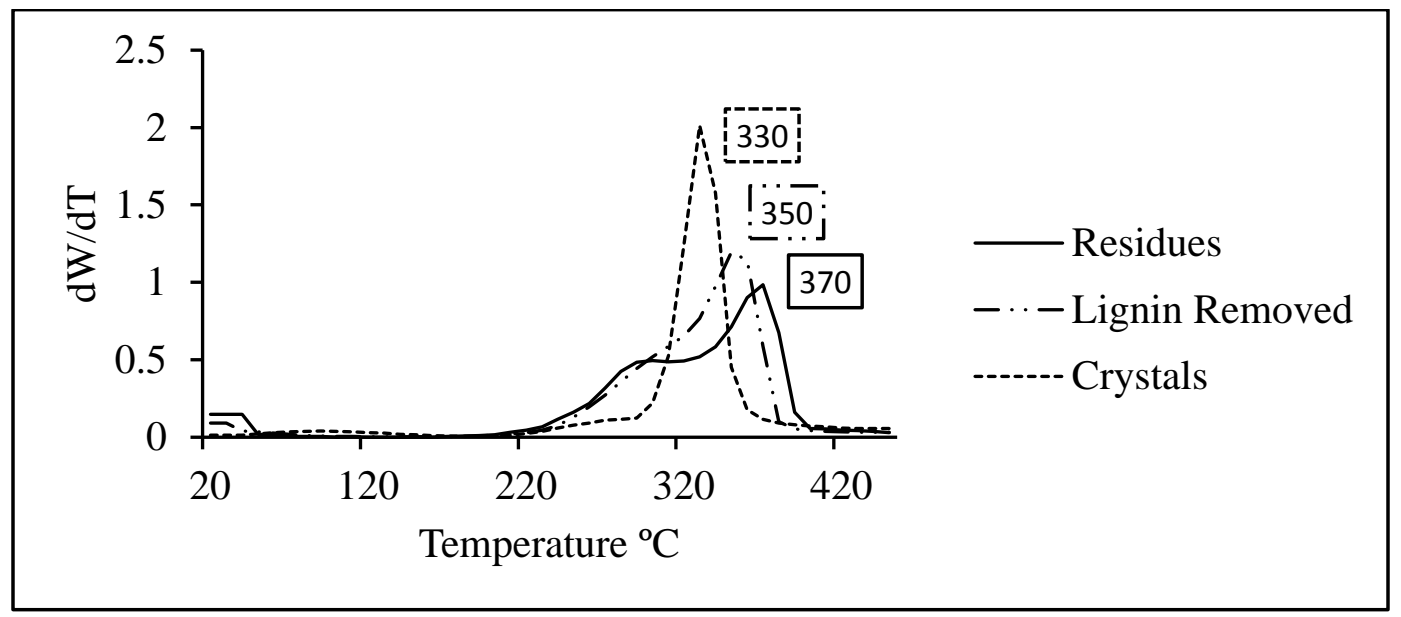

Figure 2.6. DTGA curves of red oak 2005 (heartwood) residues, lignin removed residues, and cellulose nanocrystals; maxima temperatures boxed. 
Figure 2.6 illustrates a noticeable 2 step thermal decomposition process of red oak residues and lignin removed residues, and a much less noticeable 2 step thermal decomposition of cellulose nanocrystals. This 2 step degradation process is occurring because the hemicellulose within the red oak residues and lignin removed residues is decomposing within the first step, while the cellulose (and some lignin) is decomposing within the second step. Figure 2.6 also reveals that the maximum peak in regards to thermal degradation or "maxima" of the cellulose nanocrystals is much higher $(\sim 2)$, at a temperature of $330{ }^{\circ} \mathrm{C}$, than the red oak residues and lignin removed residues $(\sim 1)$, at a temperatures of $370{ }^{\circ} \mathrm{C}$ and $350{ }^{\circ} \mathrm{C}$, respectively. This finding confirms that the majority of the remaining lignins were removed during nanocrystal formation, however, the crystal maxima is considerably greater than previous results have indicated at similar conditions (Paralikar, 2006). A large quantity of amorphous cellulose (instead of pure crystalline cellulose) could be causing this variability in results because amorphous cellulose degrades at a lower temperature and faster rate than crystalline cellulose. Thermal degradation data confirms the presence of amorphous cellulose within the specimens discussed in the previous section. DTGA curves look quite similar for both heartwood and sapwood samples (Figure 2.7 and 2.8), indicating that lignin removal and nanocrystal formation is not affected by the different chemical compositions in heartwood and sapwood. 


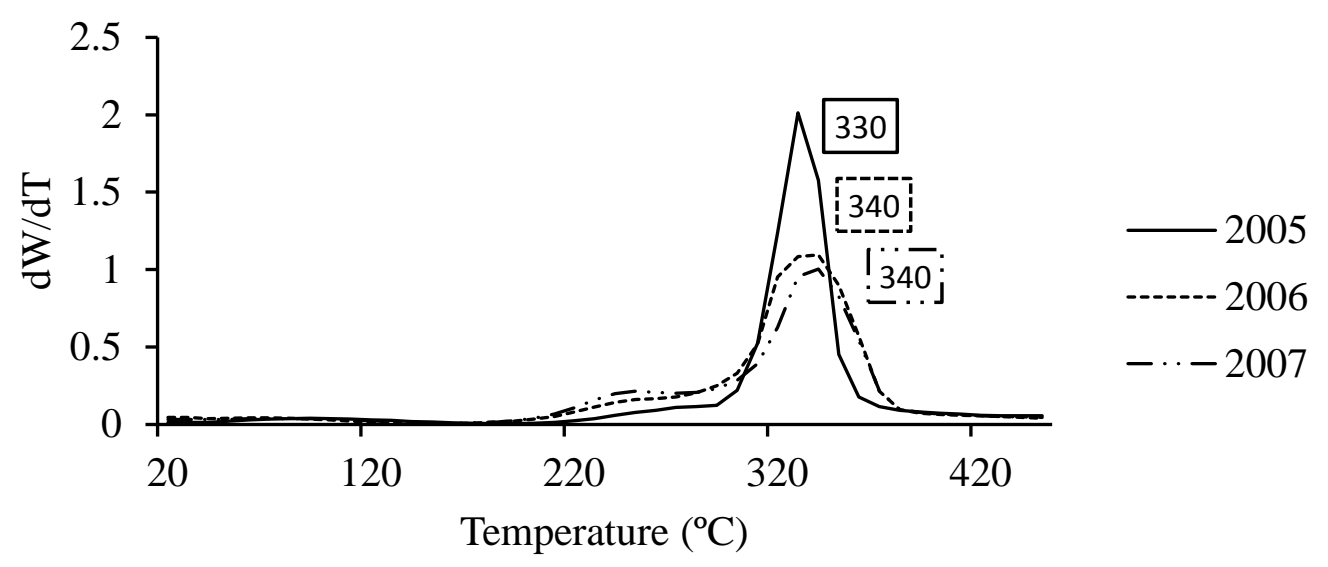

Figure 2.7. DTGA curves of cellulose 2005, 2006, and 2007 (heartwood) nanocrystals; maxima temperatures boxed.

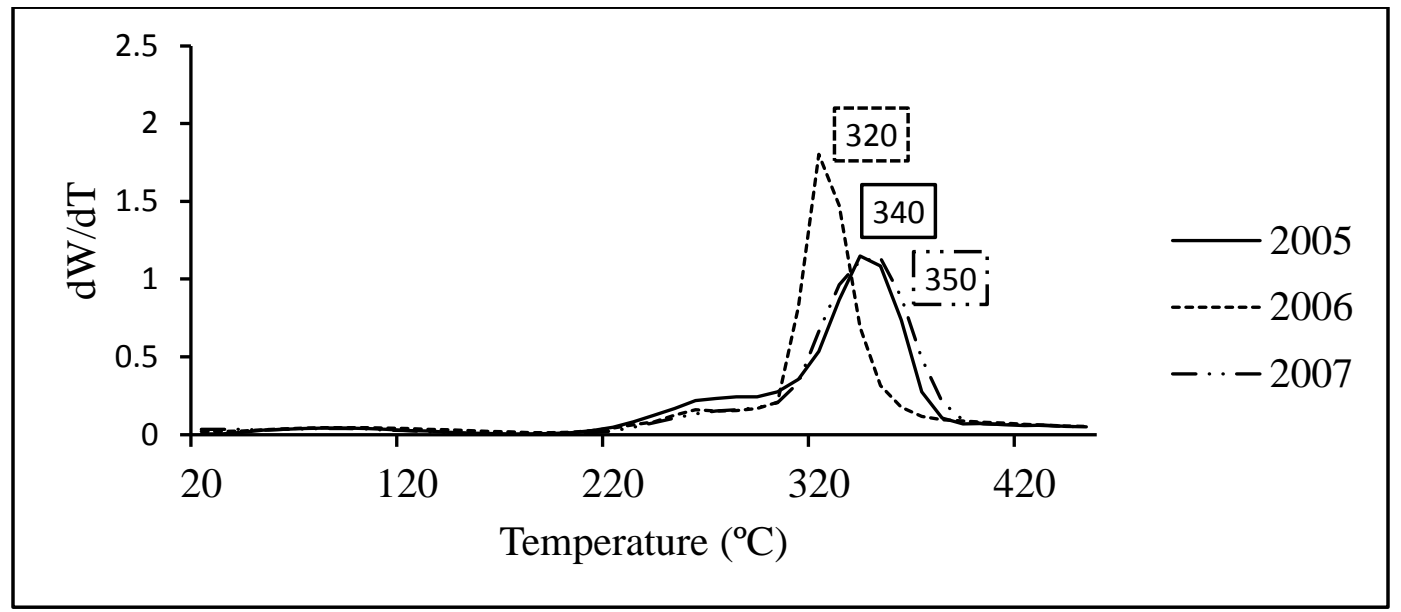

Figure 2.8. DTGA curves of cellulose 2005, 2006, and 2007 (sapwood) nanocrystals; maxima temperatures boxed.

DTGA curves also indicate the peak maxima of any one sample is randomly distributed, with no one year $(2005,2006$, or 2007) consistently exhibiting a higher peak in relation to other years. 
The two highest maxima are experienced in cellulose 2005 (heartwood) nanocrystals, and cellulose 2006 (sapwood) nanocrystals, which are much higher than literature values $(\sim 2)$ at slightly lower temperatures $\left(330{ }^{\circ} \mathrm{C}\right.$ and $320{ }^{\circ} \mathrm{C}$, respectively), while all other maxima occurred within the normal range (Paralikar, 2006), at expected temperatures. These results confirm that processing variations, such as hydrolysis time and temperatures for nanocrystal formation, occurred during sample preparation and effected the overall composition of the materials, whereas year and type appear not to influence the thermal degradation behaviors of the composite constituent materials. Heartwood and sapwood composites themselves degraded in a similar fashion to their constituent materials, including PVA (Figures 2.9 and 2.10).

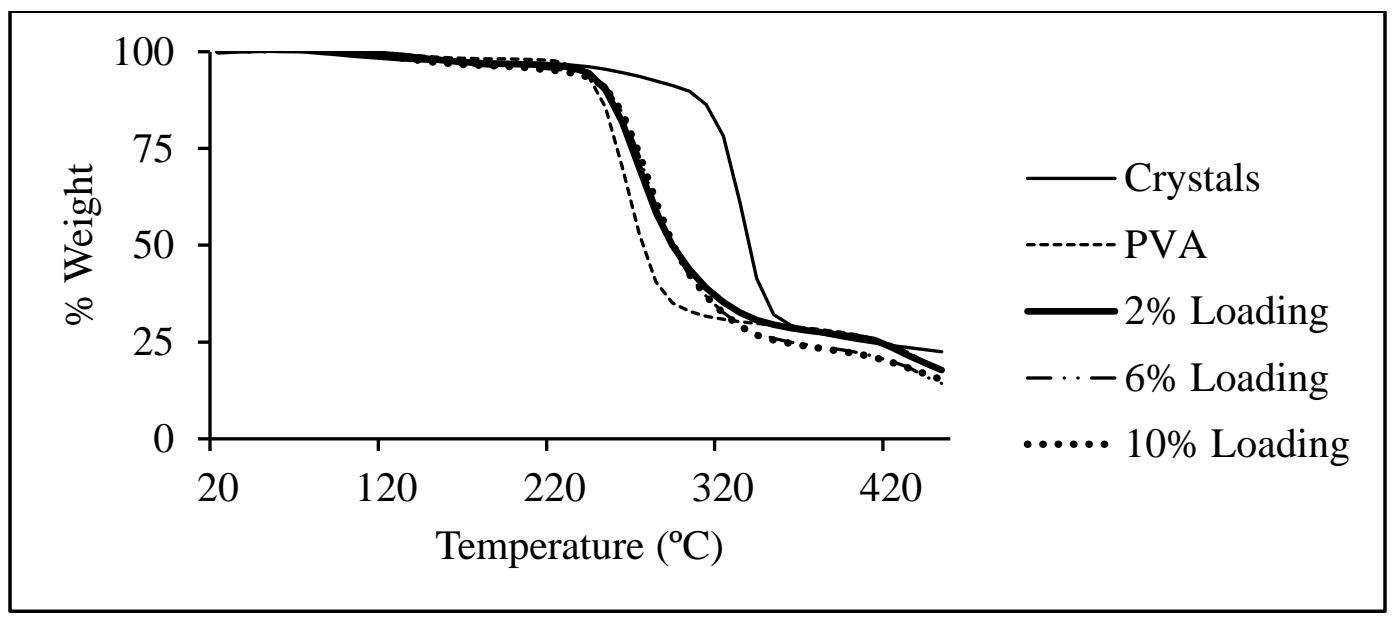

Figure 2.9. Percentage Weight Loss versus Temperature curvatures for cellulose 2005 (heartwood) nanocrystals, composites (2\%, 6\%, and 10\% loading levels), and PVA. 


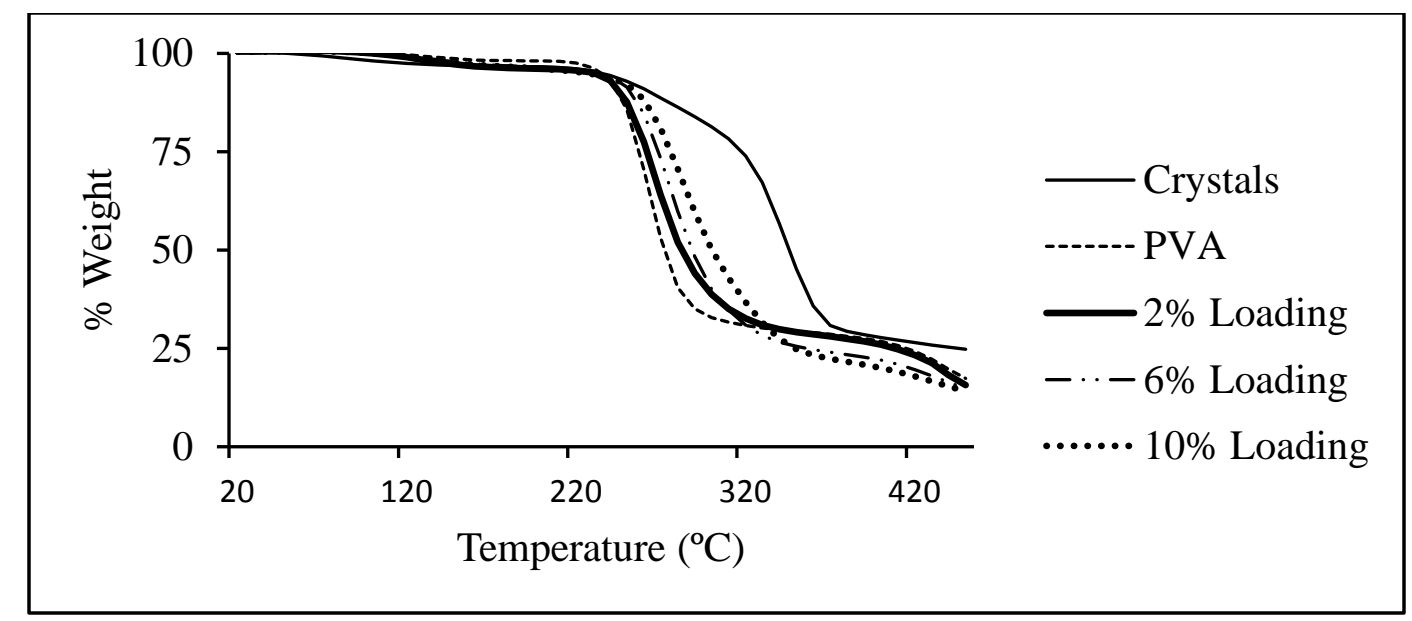

Figure 2.10. Percentage Weight Loss versus Temperature curvatures for cellulose 2005 (sapwood) nanocrystals, composites $(2 \%, 6 \%$, and $10 \%$ crystal loading levels), and PVA.

Percentage Weight Loss versus Temperature curvatures were similar for both 2006 and 2007 composites, therefore, no graphs are presented. Figures 2.9 and 2.10 indicate that PVA exhibits thermal degradation at a lower temperature than cellulose nanocrystals. This result is confirmed by literature values (Singh, 2010), (Holland and Hay, 2001). It is apparent that the mixture of PVA with cellulose nanocrystals causes the nanocomposites to degrade at a lower temperature than cellulose nanocrystals, but at a higher temperature than PVA. DTGA curves given in Figures 2.11 and 2.12 confirm these results. 


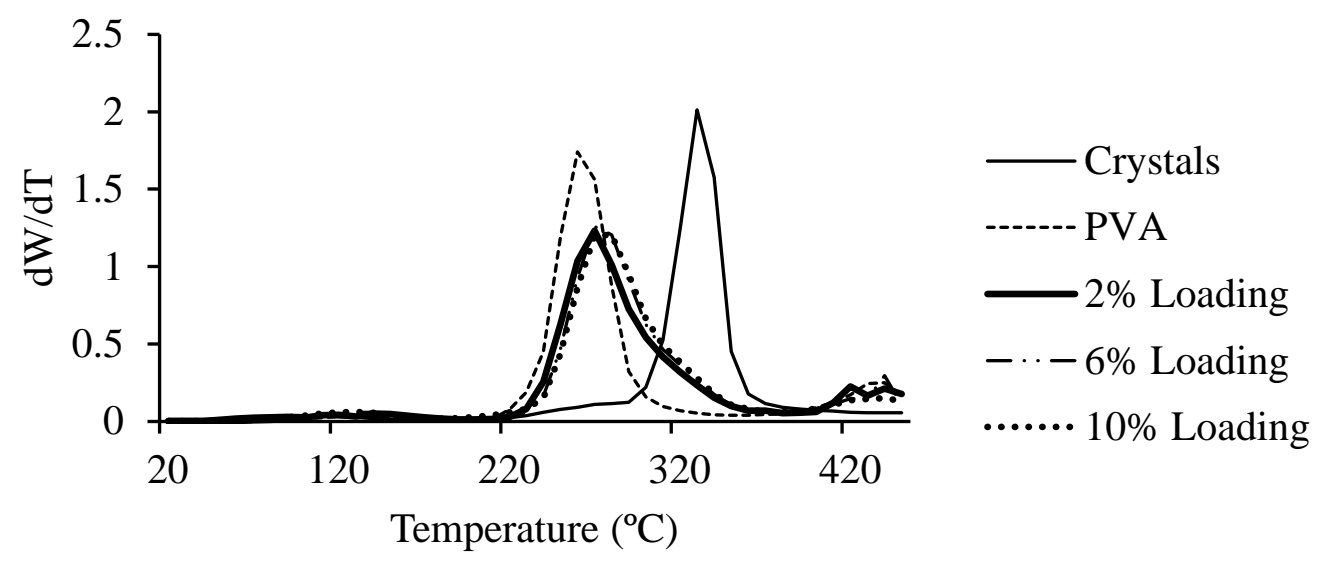

Figure 2.11. DTGA curves of cellulose 2005 (heartwood) nanocrystals, composites (2\%, 6\%, and $10 \%$ loading levels), and PVA.

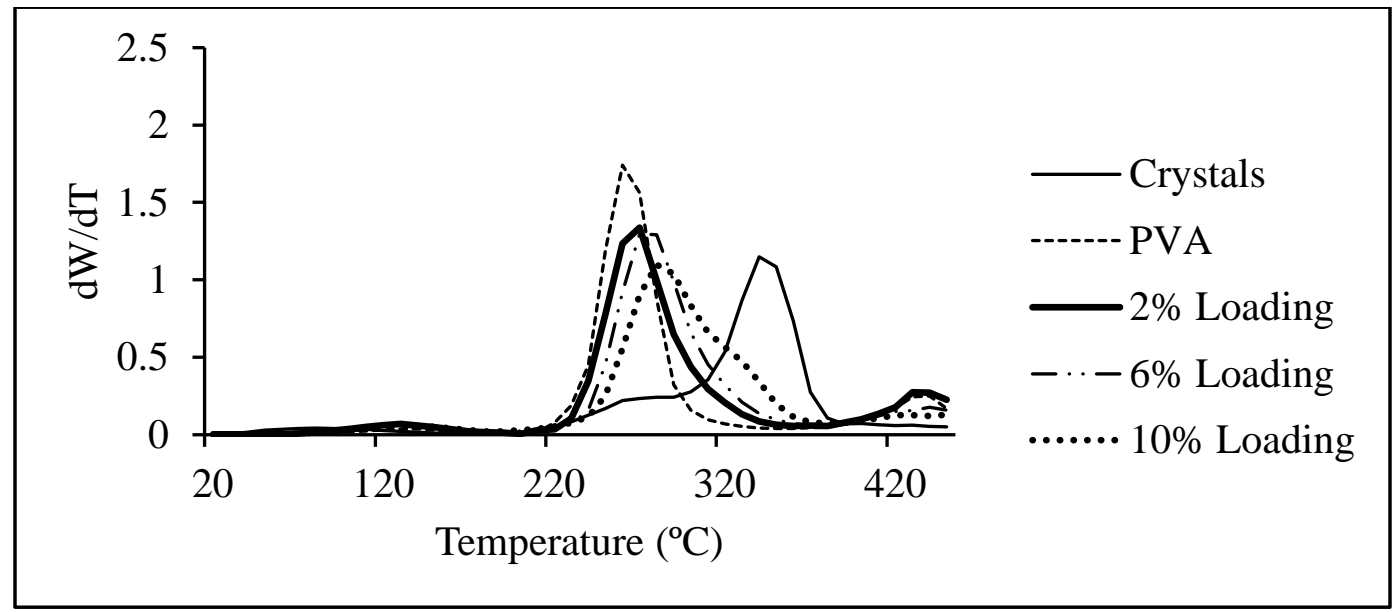

Figure 2.12. DTGA curves of cellulose 2005 (sapwood) nanocrystals, composites (2\%, 6\%, and 10\% loading levels), and PVA.

Figures 2.11 and 2.12 also indicate that while the cellulose nanocrystals and PVA DTGA curves experience a smooth downward slope during thermal degradation (right hand side of curve), the 
composites have a noticeable transition or "bump" and experience a second maxima, which becomes increasingly apparent as crystal loading levels increase. This transition in degradation occurs because of the 2 different composite constituents are degrading at different temperatures, with PVA degradation occurring first followed by cellulose crystal thermal decomposition.

\subsubsection{Tensile Mechanical Properties}

Figure 2.13 along with Table 2.4 summarize mechanical data received for tensile strength and tensile elastic modulus for all years (2005, 2006, and 2007) and type (heartwood and sapwood) of cellulosic nanocomposites, along with materials constructed with neat PVA.

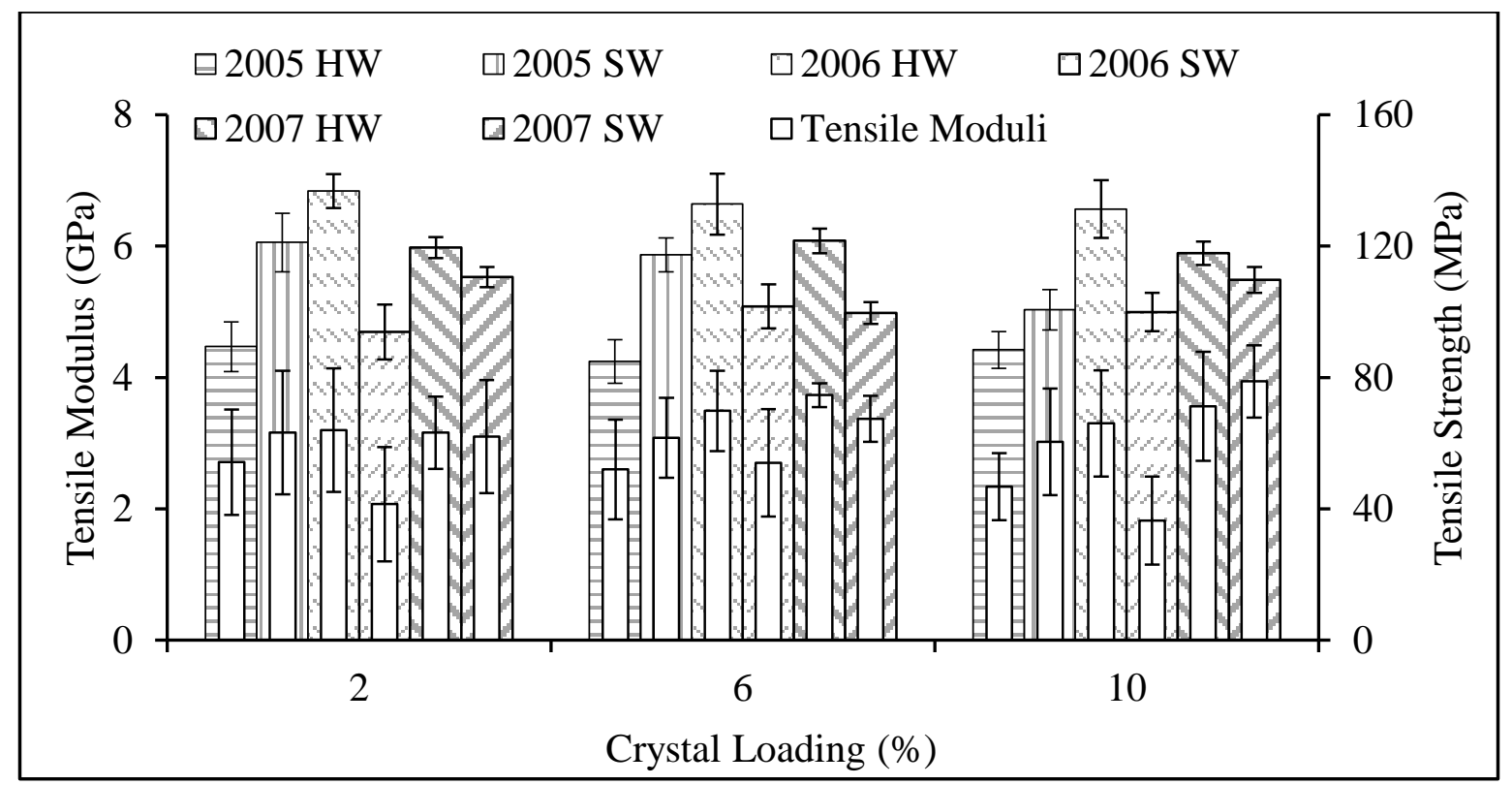

Figure 2.13. Summary of tensile mechanical data, $\mathrm{I}=$ Standard Deviation, 5 tests conducted per specimen. 
Table 2.4. Summary of tensile mechanical data.

\begin{tabular}{|c|c|c|c|}
\hline Specimen & $\begin{array}{c}\text { Crystal Loading } \\
(\%)\end{array}$ & $\begin{array}{c}\text { Tensile Strength } \\
(\mathrm{MPa})\end{array}$ & $\begin{array}{c}\text { Tensile Modulus } \\
(\mathrm{GPa})\end{array}$ \\
\hline Polyvinyl alcohol & N/A & $67.81 \pm 1.12$ & $1.45 \pm 0.30$ \\
\hline Red oak 2005 (heartwood) & 2 & $89.35 \pm 7.60$ & $2.71 \pm 0.80$ \\
\hline Red oak 2005 (heartwood) & 6 & $84.89 \pm 6.62$ & $2.60 \pm 0.76$ \\
\hline Red oak 2005 (heartwood) & 10 & $88.39 \pm 5.59$ & $2.34 \pm 0.51$ \\
\hline Red oak 2005 (sapwood) & 2 & $121.12 \pm 8.91$ & $3.16 \pm 0.71$ \\
\hline Red oak 2005 (sapwood) & 6 & $117.31 \pm 5.21$ & $3.08 \pm 0.85$ \\
\hline Red oak 2005 (sapwood) & 10 & $100.59 \pm 6.18$ & $3.02 \pm 0.41$ \\
\hline Red oak 2006 (heartwood) & 2 & $136.77 \pm 5.17$ & $3.20 \pm 0.94$ \\
\hline Red oak 2006 (heartwood) & 6 & $132.78 \pm 9.29$ & $3.49 \pm 0.61$ \\
\hline Red oak 2006 (heartwood) & 10 & $131.25 \pm 8.81$ & $3.3 \pm 0.81$ \\
\hline Red oak 2006 (sapwood) & 2 & $93.87 \pm 5.25$ & $2.07 \pm 0.87$ \\
\hline Red oak 2006 (sapwood) & 6 & $101.61 \pm 2.72$ & $2.70 \pm 0.82$ \\
\hline Red oak 2006 (sapwood) & 10 & $99.9 \pm 2.83$ & $1.82 \pm 0.67$ \\
\hline Red oak 2007 (heartwood) & 2 & $119.54 \pm 6.07$ & $3.16 \pm 0.55$ \\
\hline Red oak 2007 (heartwood) & 6 & $121.59 \pm 2.48$ & $3.73 \pm 0.18$ \\
\hline Red oak 2007 (heartwood) & 10 & $117.82 \pm 3.15$ & $3.56 \pm 0.83$ \\
\hline Red oak 2007 (sapwood) & 2 & $110.54 \pm 4.64$ & $3.10 \pm 0.86$ \\
\hline Red oak 2007 (sapwood) & 6 & $99.60 \pm 4.53$ & $3.37 \pm 0.35$ \\
\hline Red oak 2007 (sapwood) & 10 & $109.69 \pm 13.75$ & $3.94 \pm 0.55$ \\
\hline
\end{tabular}

\pm Standard Deviation, 5 tests conducted per specimen 
Upon initial statistical testing, Analysis of Variances (ANOVA's) at the 5\% significance level ( $\alpha$ $=0.05$ ) indicated differences in tensile strength and elastic modulus between neat PVA samples and cellulosic nanocomposite materials. Also, these ANOVA's revealed that crystal loading level $(2 \%, 6 \%$, and $10 \%)$ did not influence tensile mechanical properties, however, differences were present within year $(2005,2006$, and 2007), and type (heartwood and sapwood) between the cellulosic nanocomposites. After further statistical analysis, i.e. Tukey Kramer's multiple range tests, along with investigation of Figure 2.13 and Table 2.4, it was apparent that; 1) all nanocomposite samples, regardless of year or type, are significantly stronger than PVA in terms of tensile strength, however, the tensile modulus of red oak 2005 (heartwood) and red oak 2006 (sapwood), are not different from PVA, 2) the specimens that are suspected to contain higher amounts of amorphous cellulose, red oak 2005 (heartwood) and red oak 2006 (sapwood), are weaker (tensile strength) than composites containing more crystalline cellulose, 3 ) there is no pattern of increase or decrease in tensile strength or tensile modulus between years, types, or crystal loading level, and 4) tensile strength increases and decreases are coupled with tensile modulus increases and decreases. However, it should be noted that large variances experienced within the cellulosic nanocomposites in regards to tensile strength, may have influenced the statistical results. These high variances associated with tensile strength can possibly be attributed to the agglomeration of cellulosic nanocrystals within the nanocomposite materials.

Results confirm that the previous sections suggestions that red oak 2005 (heartwood) and red oak 2006 (sapwood) indeed contain more amorphous cellulose (which is weaker than crystalline cellulose) than other specimens. Also, it is apparent that a $2 \%$ loading level is sufficient for desired increases in strength qualities and higher loading levels are not necessary. Other works have attempted crystal loading levels of up to $20 \%$, and have not demonstrated 
greater tensile strengths or tensile moduli than the results obtained during this study (Paralikar, 2006). It should also be noted that at higher crystal loading levels, the ductility of the samples greatly decreases. This could be due to the fact that the cellulosic materials are more brittle than the matrix material (PVA), or an increase in agglomeration as crystal loading levels increases (Figure 2.14).

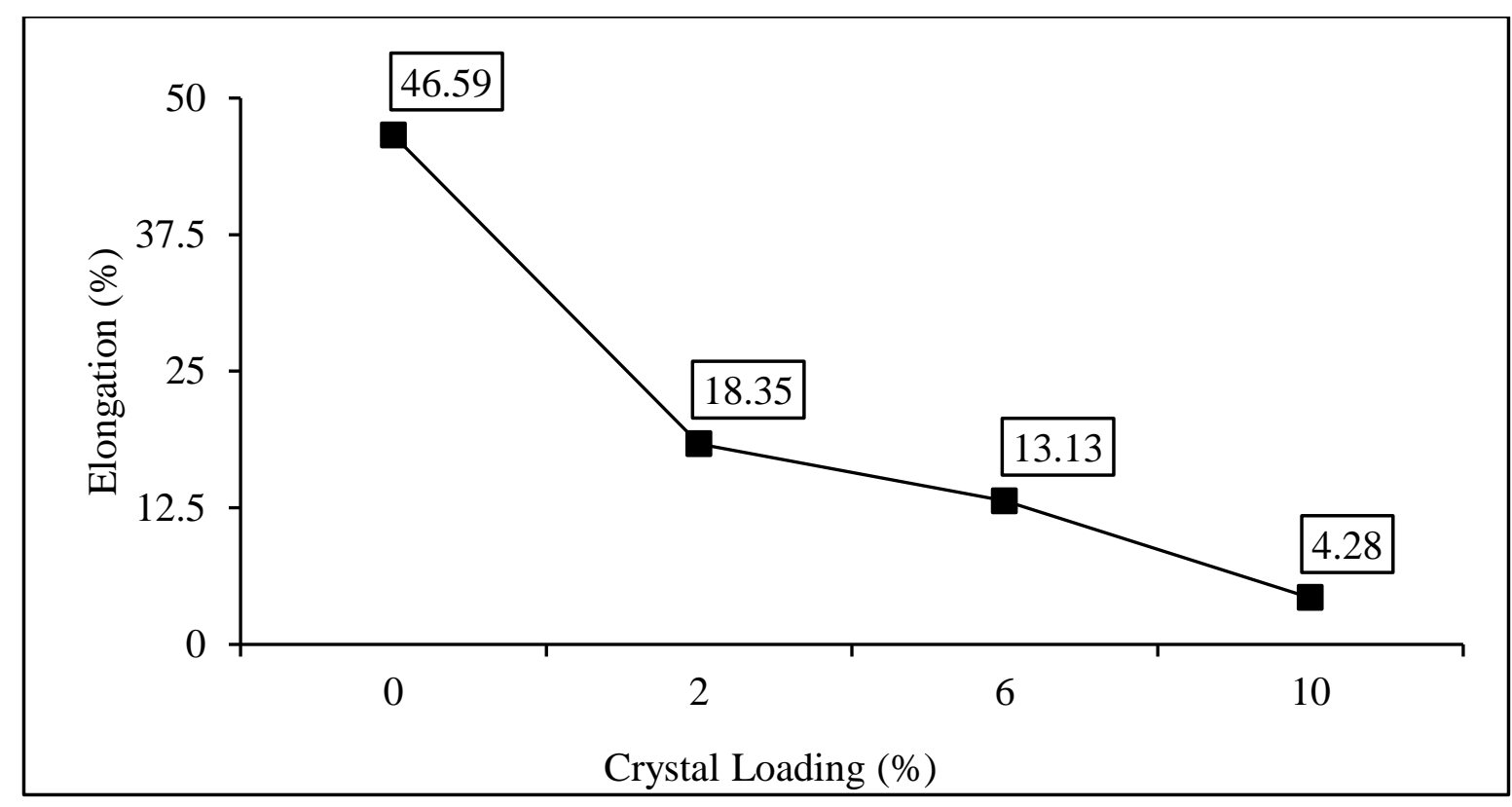

Figure 2.14. Elongation to break behaviors of cellulose nanocomposites at $2 \%, 6 \%$, and $10 \%$, crystal loading levels (PVA $=0 \%$ crystal loading); exact elongation percentages boxed.

\subsection{Conclusions}

Morphology and thermal results obtained in this research indicate that the methods used for lignin removal were successful, while the hydrolysis methods used for nanocrystal isolation did not completely hydrolyze the materials; i.e. removal of all amorphous cellulose and creation 
of individual cellulose nanocrystals was not fully realized. One solution to this problem is to increase the time, temperature, or concentration of sulfuric acid during the nanocrystal isolation hydrolysis process. It is also apparent from the Weight Loss versus Temperature and DTGA curvatures obtained from the thermo gravimetric analysis, that the composite materials, while maintaining the same pattern of thermal degradation as their respective constituent materials, decompose at slighter higher temperatures than neat PVA, and that decomposition temperature increases as crystal loading level increases.

Mechanically, all cellulosic nanocomposites, regardless of crystal loading level, outperformed neat PVA in regards to tensile strength and tensile modulus, however, this increase in strength was coupled with a reduction in elongation to break. The reduction in elongation to break behavior of the samples increased as loading level increased. This decrease in ductility is explained by the natural brittleness of the cellulosic materials in comparison with PVA, and suggests that as crystal loading level increases, agglomeration of cellulosic materials within the nanocomposites increases.

Results found in this study confirm that Appalachian hardwoods are possible to use in nanocomposite formation and that these composites exhibited increases in thermal degradation temperatures, tensile strength, and elastic tensile modulus. 


\section{References}

Adebayo, A., Wang, J., Dawson-Andoh, B., McNeel, J.F., and Armstrong, J.P. (2009). Assessment of Appalachian hardwood residue properties and potentials for bioenergy utilization. Wood and Fiber Science, 41(1), 74-83.

ASTM. (2008). Standard test method for tensile properties of plastics by use of microtensile specimens. ASTM-D 1708-08a. AMERICAN SOCIETY FOR TESTING AND MATERIALS, West Conshohocken, Pa.

Candanedo, S.B., Roman, M., and Gray, D.G. (2005). Effect of reaction conditions on the properties and behavior of wood cellulose nanocrystal suspensions. Biomacromolecules, 6, 1048-1054.

Cheng, Q., Siqun, W., and Rials, T.G. (2008). Poly(vinyl alcohol) nanocomposites reinforced with cellulose fibrils isolated by high intensity ultrasonication. Composites: Part A, 40, 218-224.

Cheng, Q., Wang, S., Rials, T.G., and Lee, S.H. (2007). Physical and mechanical properties of polyvinyl alcohol and polypropylene composite materials reinforced with fibril aggregates isolated from regenerated cellulose fibers. Cellulose, 14, 593-602.

Choi, Y., and Simonsen, J. (2006). Celluose nanocrystal-filled carboxymethyl cellulose nanocomposites. Nanoscience and Nanotechnology, 6(3), 633-639.

Forest Products Laboratory. (1999). Wood handbook: wood as an engineering material. Chapter 3: Structure and Function of Wood. Madison, WI: U.S. Department of Agriculture, Forest Service, Forest Products laboratory. 
Holland, B.J., and Hay, J.N. (2001). The thermal degradation of poly (vinyl alcohol). Polymer, 42, 6775-6783.

Kentaro, A., Shinichiro, I., and Hiroyuki, Y. (2007). Obtaining cellulose nanofibers with a uniform width of $15 \mathrm{~nm}$ from wood. Biomacrimolecules, 8, 3276-3278.

Lewin, M. (2007). Handbook of fiber chemistry, 3rd edition. Page 808. Boca Raton, FL: CRC Press.

Paralikar, S. (2006). Poly (vinyl alcohol) / cellulose nanocomposite barrier films (Master thesis, Oregon State University, 2006).

Singh, K. (2010). Biomass Pyrolysis. PowerPoint lecture presented at West Virginia University. Flinn Scientific Incorporated. (2007). Preparation of polyvinyl alcohol and slime. Retrieved from http://www.flinnsci.com/Documents/demoPDFS/Chemistry/CF0608.00.pdf

U.S. Department of Energy (DOE) and U.S. Department of Agriculture (USDA). (2005). Biomass as feedstock for a bioenergy and bioproducts industry: the technical feasibility of a billion - ton annual supply DOE/GO-102995-2135. Washington, DC.

Wise, L.E., Murphy, M., and D’Addieco, A. A. (1946). Chlorite holocellulose, its fractionation and bearing on summative wood analysis and studies on the hemicelluloses. Paper Trade Journal. 122, 35-43. 
CHAPTER 3: WATER VAPOR TRANSMISSION AND SOLUBILITY PROPERTIES OF CELLULOSIC NANOCOMPITE BIOFILMS

To be submitted to Forest Products Journal. 


\begin{abstract}
Red oak (heartwood and sapwood) cellulose nanocrystals were isolated through a combination of acid hydrolysis, ultrasonication, and homogenization. Nanocrystal suspensions were then combined with a polyvinyl alcohol (PVA) solution to form fully biodegradable cellulosic nanocomposite biofilms, via film casting. Biofilms were then analyzed for water vapor transmission and solubility properties. Results obtained revealed that water vapor transmission rates in heartwood samples were similar to those experienced in neat PVA; however, sapwood samples saw a significant decrease in transmission rates at the $2 \%$ and $6 \%$ loading levels. Neither heartwood, nor sapwood composites hindered water vapor transmission at $10 \%$ crystal loading levels possibly due to agglomeration. Solubility testing revealed that although heartwood samples followed the same general pattern of solubility to water as neat PVA, sapwood samples were able to remain intact at a wide range of temperatures, while being submerged in water. All data found during this research suggested that although there were differences in heartwood and sapwood composites in regards to water vapor transmission and solubility, that these differences were only experienced due to initial processing variations that allowed for heartwood samples to retain significant amounts of amorphous cellulose. These materials are expected to be very useful for packaging and food barrier devices that are safe to the consumer and biodegradable.
\end{abstract}




\subsection{Introduction}

Products that currently use polyvinyl alcohol (PVA) or some other type of plastic polymer have potential to be reinforced with filler materials, which can alter mechanical stability, thermal degradation, biodegradability, and barrier properties of the completed composite materials.

When making a composite product, the goal is to enhance certain qualities or properties of the composite constituent materials. Of course, limitations of any raw material (PVA, filler materials) in composite formation can possibly affect the overall serviceability of the products themselves. One such limitation associated with PVA, is its ability to remain intact while being subjected to water, in both vaporous and liquid forms (Chan et al., 1999).

The lack of resistance to water makes the use of PVA appealing in the terms of biodegradability, but problematic in applications such as food packaging, where materials may be subject to humidity and water. Therefore, it is critical to use filler or reinforcing materials that not only enhance water barrier properties of neat PVA, but also are environmentally friendly and biodegradable, such as cellulosic nanocrystals.

Recently, there have been many studies regarding the reinforcement of PVA with cellulosic nanocrystals and the formation of cellulosic nanocomposites (Dogan and McHugh, 2007), (Michailova et al., 2005). This renewed interest is attributed to the fact that cellulose nanocrystals positively affect the strength and water barrier properties of PVA, and are 100\% biodegradable. These investigations are critical, because applications for cellulosic nanocomposites, in particular PVA composites reinforced with cellulose nanocrystals, are abundant. Research related to the production of barrier films for packaging, and even on 
protective edible films that are placed on the food itself, has been implemented by the paper products and packaging industries (Dogan and McHugh, 2007). The pharmaceutical industry has shown interest in creating a cellulosic nanocomposite that will host drugs and later release it once inside the body (Michailova et al., 2005). Several applications for nanocomposites within the medical field are also being investigated, such as use for kidney dialysis, heart valves, bone replacement materials, and skin grafts (Simonsen, 2008).

Although it is clear that cellulose nanocrystals can improve neat PVA in terms of mechanical, barrier, and biodegradability properties, these materials also have potential for incorporation into a wide variety of applications. However, the influences on barrier behaviors when incorporating hardwood cellulose nanocrystals into a PVA matrix are unknown. Therefore, this research was designed to examine barrier behaviors of red oak cellulosic nanocomposites; including water vapor transmission and solubility.

\subsection{Materials and Methods}

\subsubsection{Composite Formation}

In 2007, red oak (Quercus rubra) residues were collected from 2005 harvest sites located within West Virginia for processing (Adebayo et al., 2009). Residues were then subjected to processing, lignin removal, nanocrystal isolation, and were subsequently incorporated in a polyvinyl alcohol (PVA) matrix to form cellulosic nanocomposite biofilms at 3 crystal loading levels; 2\%, 6\%, and 10\% (Jacobson et al., 2011). These nanocomposite biofilms were then evaluated for water vapor transmission and solubility properties. 


\subsubsection{Water Vapor Transmission}

Water vapor transmission rates were determined by a method adapted from (Choi and Simonsen, 2006). Three glass jars were filled with 50 milliliters (ml) of distilled water. Films of 41.15 millimeters $(\mathrm{mm})$ in diameter, and 127 microns $(\mu \mathrm{m})$, or 0.005 inches (in) thick, were glued with water proof resin to the tops of the glass jars ( 3 specimens at each loading level, 9 total specimens). The initial weights of the assemblies were then recorded using a Denver MAXX scale (Model MXX -123), with a capacity of 120 grams (g) and a resolution of $0.001 \mathrm{~g}$. All samples were stored at room conditions, with a temperature of approximately $20{ }^{\circ} \mathrm{Celsius}(\mathrm{C})$ and relative humidity (RH) of $30 \%$ for several weeks. During this time period weights were recorded until a constant flux was observed for 3 consecutive days, which was the average flux. Water vapor transmission rates were then determined using the following formula:

$$
\mathbf{J}=\frac{\mathrm{m}}{\mathrm{axt}}
$$

Where: $\mathbf{J}=$ mass flux $\left(\mathrm{g} / \mathrm{m}^{2}\right)$

$\mathbf{m}=$ weight change by loss of water in 24 hours $(\mathrm{g})$

$\mathbf{a}=$ area of film available for mass transfer $\left(\mathrm{m}^{2}\right)$

$\mathbf{t}=$ time (number of days)

Water vapor transmission tests were also conducted by use of a Dynamic Vapor Sorption (DVS, Advantage Model) automated multi-vapor gravimetric analyzer, owned and operated by Surface

Measurement Systems (SMS) Ltd. Films of $5 \mathrm{~mm}$ in diameter, and $127 \mu \mathrm{m}$ thick, were cut and 
placed on to a metal container filled with a desiccant (dry zeolite). Films were then sealed to the container preventing any water vapor from escaping during testing via o-rings. After sealing, specimens were exposed to a continuous flow of water vapor at a temperature of $23{ }^{\circ} \mathrm{C}$. The zeolite mass changes (g) were then measured continuously for 6 hours, and these changes in mass as a function of time (hour) were recorded and plotted. A mass flux equation, similar to the equation given previously, was then used to calculate the water vapor transmission rates of the materials. Data obtained from SMS were compared to results obtained by the glass jar method of water vapor transmission rate determination, to confirm the accuracy of testing.

\subsubsection{Water Solubility}

Utilizing a method adapted from (Chan et al., 1999), the water solubility's of nanocomposite films were determined. Twenty-five sections, $127 \mathrm{~mm}$ by $127 \mathrm{~mm}$, were cut from casted composites at each nanocrystal loading level (total of 75 specimens). All 75 specimens were then oven dried (Thermo Fisher Scientific, Model 6524 ) at $50{ }^{\circ} \mathrm{C}$ until constant weights were obtained. Upon drying, initial weights (WeightI) of the specimens were recorded. Five 100 $\mathrm{ml}$ beakers were filled with $80 \mathrm{ml}$ of distilled water and covered with aluminum foil. Covered beakers were then placed into an oven and heated to the desired temperatures. After constant temperatures were reached within the beakers of distilled water, 5 films were placed in 5 separate beakers, covered, and heated for 24 hours. This process was completed a total of 5 times for each loading level, at the following water temperatures; room temperature $\left(\sim 20^{\circ} \mathrm{C}\right)$, as well as, 40 , 50, 60, and $70{ }^{\circ} \mathrm{C}$. Specimens were removed and placed on to plastic Petri dishes and dried to 
constant weights in an oven set at $50{ }^{\circ} \mathrm{C}$. Final weights (WeightF) were then recorded and water solubility's of samples were obtained using the following formula

$$
\text { Weight Loss }(\%)=\frac{\text { WeightI-WeightF }}{\text { WeightI }} \times 100
$$

Where: Weight Loss $=$ water solubility of films $(\%)$

WeightI = weight initial $(g)$

WeightF $=$ weight final $(\mathrm{g})$

\subsection{Results and Discussion}

\subsubsection{Water Vapor Transmission Properties}

Table 3.1 and Figure 3.1 summarize results obtained during water vapor transmission testing. 
Table 3.1. Summary of water vapor transmission data.

\begin{tabular}{ccc}
\hline Specimen & $\begin{array}{c}\text { Crystal Loading } \\
(\%)\end{array}$ & $\begin{array}{c}\text { Flux } \\
\left(\mathrm{g} / \mathrm{m}^{2} / 24 \text { hour }\right)\end{array}$ \\
\hline PVA Films & 0 & $45.14 \pm 1.32$ \\
Heartwood Films & 2 & $39.35 \pm 2.33$ \\
Heartwood Films & 6 & $39.14 \pm 2.91$ \\
Heartwood Films & 10 & $47.76 \pm 5.65$ \\
Sapwood Films & 2 & $23.35 \pm 2.15$ \\
Sapwood Films & 6 & $25.24 \pm 3.12$ \\
Sapwood Films & 10 & $44.27 \pm 7.89$ \\
\hline
\end{tabular}

\pm Standard Deviation, 3 tests conducted per specimen

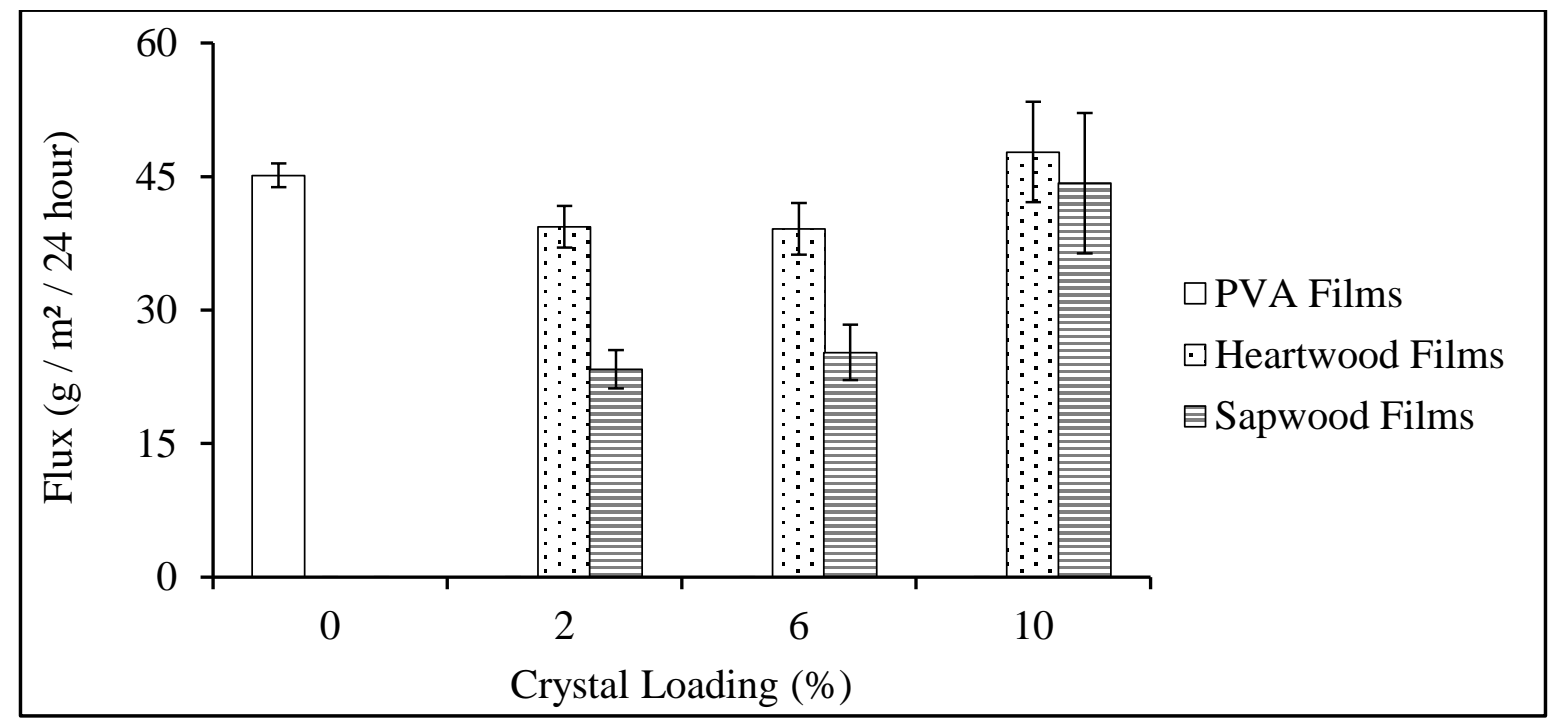

Figure 3.1. Summary of water vapor transmission data; $I=$ Standard Deviation, 3 tests conducted per specimen. 
Results found during water vapor transmission testing indicate that heartwood nanocomposites experience no significant $(\alpha=0.05)$ difference in the flux rate of water vapor transmission, when compared to neat PVA. Sapwood composite materials exemplify a significant decrease in water vapor transmission rate within the $2 \%$ and $6 \%$ loading levels, but only experiences marginal differences at the $10 \%$ loading level. As indicated in a previous study (Jacobson et al., 2011), heartwood samples differ from sapwood samples in regards to the amount of crystalline and amorphous cellulose contained within the composites. Crystalline cellulose has the ability to inhibit the pathways available for water vapors to diffuse through barrier materials (Azeredo et al., 2011), which is shown in Figure 3.2.

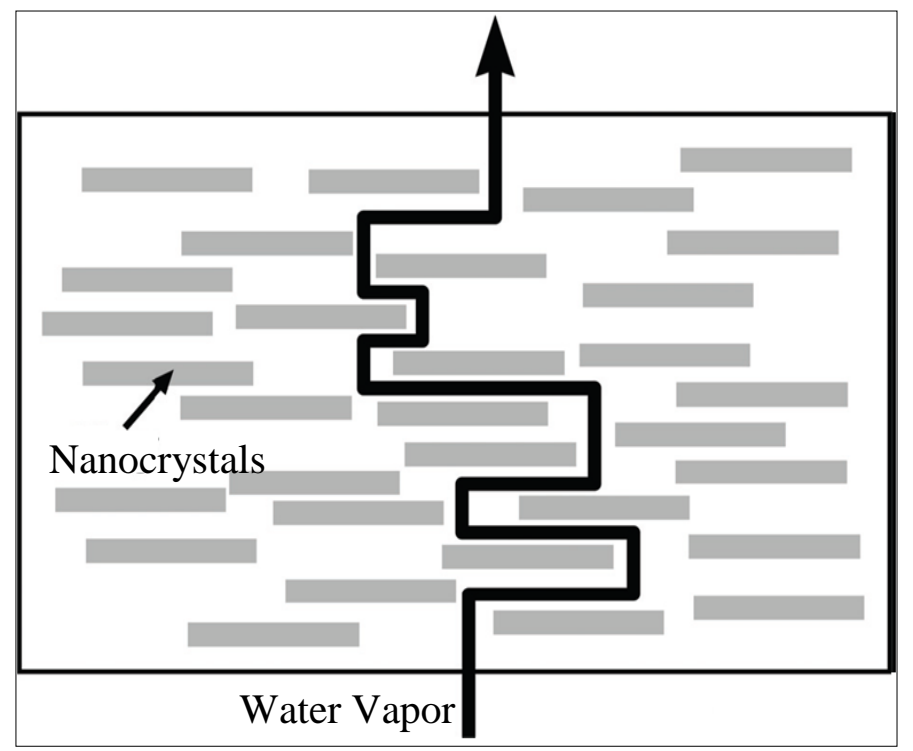

Figure 3.2. Water vapor pathway prevention via cellulosic nanocrystals (Adapted from Azeredo et al., 2011). 
The increases in crystalline cellulose content within sapwood samples, in comparison with heartwood samples, explains why the sapwood composite materials are able to significantly slow the rate of water vapor transmission within the cellulosic biofilms. The inability to reduce water vapor transmission flow rates with $10 \%$ loading levels, in heartwood and sapwood composites, can be explained by the formation of agglomerates of cellulose within the matrix material (PVA). Agglomerates within composite materials allow for ease of permeability for vaporous materials (Saxena and Ragauskas, 2009). Results received from SMS Ltd., confirm that as loading level increases from $2 \%$ to $10 \%$, there is a reduction in the ability of cellulosic nanocomposites to reduce water vapor transmission flow rates (Table 3.2).

Table 3.2. Water vapor transmission data received from SMS Ltd.

\begin{tabular}{ccc}
\hline Specimen & $\begin{array}{c}\text { Crystal Loading } \\
(\%)\end{array}$ & $\begin{array}{c}\text { Flux } \\
\left(\mathrm{g} / \mathrm{m}^{2} / \mathrm{hour}\right)\end{array}$ \\
\hline Heartwood & 2 & 0.0210 \\
Heartwood & 10 & 0.0380 \\
\hline
\end{tabular}

\subsubsection{Water Solubility Properties}

Figure 3.3 summarize the water solubility data received during this study. 


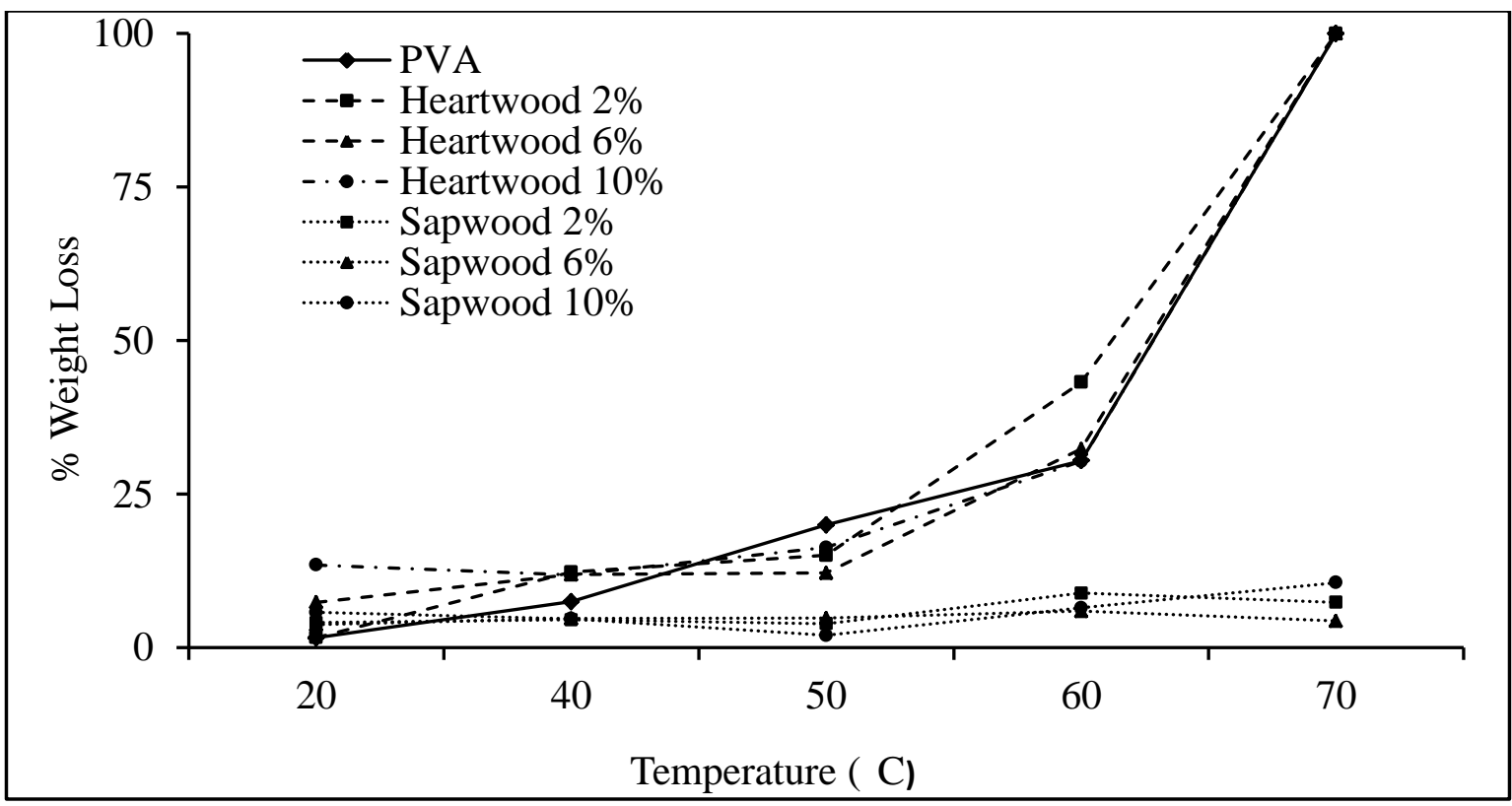

Figure 3.3. Summary of water solubility data.

It is apparent from Figure 3.3 that all heartwood samples follow the same general pattern as PVA, in regards to water solubility, and become fully soluble at $70{ }^{\circ} \mathrm{C}$. However, while each increase in temperature causes a significant solubility increase in PVA samples, this is not true for each temperature increase in heartwood samples. Specifically, for heartwood samples with $2 \%$ loading levels, significant solubility increases are not experienced within the $40-50{ }^{\circ} \mathrm{C}$ temperature range, for heartwood samples with $6 \%$ and $10 \%$ loading levels, significant temperature increases are not experienced within the $20-40{ }^{\circ} \mathrm{C}$ or the $40-50{ }^{\circ} \mathrm{C}$ temperature ranges. For all sapwood samples, there is no significant increase in solubility within the entire range of testing $\left(20-70{ }^{\circ} \mathrm{C}\right)$ and all sapwood composites did not become fully soluble until 90 $95{ }^{\circ} \mathrm{C}$. It is apparent that nanocomposite samples, regardless of type (heartwood and sapwood) or loading level $(2 \%, 6 \%$, and $10 \%)$, affect the nature of solubility when compared to neat PVA. 
This is possibly occurring because of the higher temperature at which cellulose thermally decomposes $\left(240-350{ }^{\circ} \mathrm{C}\right)$ when compared to PVA $\left(200-300{ }^{\circ} \mathrm{C}\right)$, (Jacobson et al., 2011). It also indicates that hydrogen bonding is occurring between the cellulose nanocrystals and the PVA, thus increasing the presence of bonds unbreakable by water alone (Paralikar, 2006). The large difference between sapwood and heartwood samples, in regards to water solubility, is most

likely not occurring due to inherent chemical differences between sapwood and heartwood; as such differences were either removed during pre-treatment or are minimal in nature (Gardner et al., 1990). However, the fact that the heartwood nanocomposites constructed during this research contain much more amorphous cellulose than sapwood nanocomposites explains why these differences are occurring; partly because amorphous cellulose thermally degrades at lower temperatures than crystalline cellulose, and partly because crystalline cellulose experiences better bonding mechanisms than amorphous cellulose with matrix materials (Hubbe et al., 2008).

\subsubsection{Gas Permeability}

Although gas permeability was not investigated during this study, it is important to evaluate and understand how the incorporation of hardwood cellulosic nanocrystals will influence the chemical and gas barrier properties of completed nanocomposite products. Previous research has indicated that gas permeability is affected in the same manner as water vapor transmission rates (Paralikar, 2006), in that the cellulosic nanocrystals inhibit the flow of gas through the composite materials. However, there are no available resources in regards to composites constructed with hardwood residues. Therefore, it is suggested that future research investigates the gas permeability of cellulosic nanocomposite biofilms constructed during this 
study, either by implementation of “ASTM-D1434-82”, "ASTM-F 1407-99a”, or through the use of inverse gas chromatography (IGC).

\subsection{Conclusions}

Water vapor transmission data found during this study indicate that cellulosic nanocomposite biofilm transmission rates are affected by cellulose loading levels (\%) and crystallinity of cellulose materials used for composite reinforcement. Results convey that at loading levels higher than $6 \%$, water vapor transmission rate reduction diminishes, suggesting that agglomerating cellulose allows for ease of passage for vaporous materials.

Water solubility within cellulosic nanocomposite materials were not affected by cellulose loading levels, however, crystallinity of cellulose materials used for composite formation is quite significant. Composites formed with highly crystalline cellulose did not solubize in water until temperatures reached higher levels than those observed in neat PVA and non-crystalline samples.

Water vapor transmission and water solubility results, coupled with strength and thermal data found in previous experiments (Jacobson et al., 2011), confirm that Appalachian hardwoods can be utilized for nanocomposite formation and exhibit properties that are highly preferred in the packaging industry, such as; increased tensile strength and elastic modulus, increased thermal degradation properties, a reduction in water vapor transmission rates, and a lower rate of water solubility in a wide range of temperatures. However, gas permeability properties should be evaluated before these materials are implemented in food and other packaging applications. 


\section{References}

Adebayo, A., Wang, J., Dawson-Andoh, B., McNeel, J.F., and Armstrong, J.P. (2009). Assessment of Appalachian hardwood residue properties and potentials for bioenergy utilization. Wood and Fiber Science, 41(1), 74-83.

ASTM. 1982. Standard test method determining gas permeability characteristics of plastic film and sheeting. ASTM-D 1434-82. AMERICAN SOCIETY FOR TESTING AND MATERIALS, West Conshohocken, Pa.

ASTM. 1999. Standard test method for resistance of chemical protective clothing materials to liquid permeation-permeation cup method. ASTM-F 1407-99a. AMERICAN SOCIETY FOR TESTING AND MATERIALS, West Conshohocken, Pa.

Azeredo, H.M.C., Mattoso, L.H.C., and McHugh, T.H. (2011). Nanocomposites in food packaging - a review. In B. Reddy (Ed), Advances of diverse industrial applications of nanocomposites. (pp. 1-22). InTech.

Chan, L.W., Hao, J.S., and Heng, P.W.S. (1999). Evaluation of permeability and mechanical properties of composite polyvinyl alcohol films. Chemical and Pharmaceutical Bulletin, 47(10), 1412-1416.

Choi, Y., and Simonsen, J. (2006). Cellulose nanocrystal-filled carboxymethyl cellulose nanocomposites. Nanoscience and Nanotechnology, 6(3), 633-639.

Dogan, N., and McHugh, T.H. (2007). Effects of microcrystalline cellulose on functional properties of hydroxyl propyl methyl cellulose microcomposite films. Food Science. 72(1), E16-22. 
Gardner, D.J., Generalla, N.C., Gunnells, D.W., and Wolcott, M.P. (1990). Dynamic wettability of wood. Langmuir, 7, 2498-2502.

Hubbe, M.A., Rojas, O.J., Lucia, L.A., and Sain, M. (2008). Cellulosic nanocomposites: a review. BioResources, 3(3), 929-980.

Jacobson, P., Wang, J., Cheng, Q., DeVallance, D., and Oporto, G. (2011). Characterization of red oak cellulosic nanocrystal suspensions and composites utilizing a polyvinyl alcohol matrix. Wood and Fiber Science, in submission.

Michailova, V., Titeva, S., and Kotsilkova, R. (2005). Rheological characteristics and diffusion processes in mixed cellulose hydrogen matrices. Drug Delivery Science and Technology 15(6), 443-449.

Paralikar, S. (2006). Poly (vinyl alcohol) / cellulose nanocomposite barrier films (Master thesis, Oregon State University, 2006).

Saxena, A., and Ragauskas, A.J. (2009). Water transmission barrier properties of biodegradable films based on cellulosic whiskers and xylan. Carbohydrate Polymer, 78, 357-360.

Simonsen, J. (2008). Bio-based nanocomposites: challenges and opportunities. PowerPoint lecture presented at Oregon State University. 


\section{CHAPTER 4: SUMMARY}

Results obtained during this research indicate that pre-treatment and processing of red oak (Quercus rubra) residues affects the behaviors, and thus serviceability, of cellulosic nanocomposites constructed. It was found that while the lignin removal method, utilizing acified sodium chlorite, was sufficient, the cellulose nanocrystal isolation method, implementing sulfuric acid in combination with ultrasonication and homogenization, was not fully effective because of incomplete sulfuric acid hydrolysis coupled with lack of a high speed centrifuge. This lack of effectiveness allowed for some nanocrystal suspensions, red oak 2005 (heartwood) and red oak 2006 (sapwood), to contain a higher amount of amorphous cellulose than all other suspensions. This increase in amorphous cellulose was correlated with a decrease in reinforcement and barrier properties when incorporated into a polyvinyl alcohol matrix (PVA), when compared to composites constructed with a higher degree of crystalline cellulose.

Morphologically, all red oak residues were similar in size and shape after initial grinding and processing. After lignin removal specimen particles became smaller, but did not differ much in size or shape between year $(2005,2006$, and 2007) or type (heartwood and sapwood) of delignified wood residue. Upon nanocrystal isolation, atomic force microscopy (AFM) images revealed that cellulosic particles were nano-size, or 1 - 100 nanometers (nm), in diameter, but not in length. These results, paired with yield information, revealed that while all samples still contained some amorphous cellulose, those samples that contained the most were red oak 2005 (heartwood) and red oak 2006 (sapwood).

Thermally, results obtained via thermo gravimetric analysis confirmed the morphologic and yield data, in regards to the lack of crystallinity in red oak 2005 (heartwood) and red oak 
2006 (sapwood) specimens. Composite materials, regardless of year, type, or crystal loading level, experienced thermal degradation at higher temperatures than neat PVA. Composites also maintained the same pattern of thermal decomposition as their constituent materials.

Mechanically, all nanocomposites regardless of year, type, or crystal loading level, showed significant increases in tensile strength and elastic tensile modulus, when compared to neat PVA. Results also exemplified that composites containing a higher degree of crystalline cellulose exhibited superior mechanical properties than those that contained large amounts of amorphous cellulose. However, all improvements in strength and elastic modulus were coupled with a reduction in elongation to break behaviors.

Water vapor transmission properties were improved with the addition of $2 \%$ and $6 \%$ cellulose crystal loading levels in the PVA matrix. However, this reduction in water vapor transmission was not experienced within the $10 \%$ cellulose crystal loading levels. Results also showed that only composites which utilized cellulose nanocrystals with a high degree of crystallinity experienced the reduction in water vapor transmission rates.

Solubility to water was significantly reduced at a wide range of temperatures, regardless of cellulose crystal loading level. While the neat PVA used for composite formation was $100 \%$ soluble at $70{ }^{\circ} \mathrm{C}$, composites utilizing cellulose nanocrystals were not fully soluble until $90{ }^{\circ} \mathrm{C}$. However, this reduction in solubility was only achieved through the use of highly crystalline cellulose composites.

Overall, data obtained during this research has demonstrated that hardwood residues obtained from Appalachia can successfully be incorporated into a PVA matrix, and that these cellulosic nanocomposite biofilms exhibited enhancements in strength, thermal, and water barrier properties. 